\title{
Risk and Resilience in an Acute Stress Paradigm: Evidence From Salivary Cortisol and Time-Frequency Analysis of the Reward Positivity
}

Clinical Psychological Science 2020, Vol. 8(5) 872-889 (C) The Author(s) 2020 Article reuse guidelines: sagepub.com/journals-permissions DOI: $10.1177 / 2167702620917463$ www.psychologicalscience.org/CPS @SAGE

all

\author{
Paige Ethridge ${ }^{1}$ (D) Nida $\mathrm{Ali}^{2}$, Sarah E. Racine ${ }^{1}$, \\ Jens C. Pruessner ${ }^{3}$, and Anna Weinberg ${ }^{1}$ \\ ${ }^{1}$ Department of Psychology, McGill University; ${ }^{2}$ Department of Applied Psychology, \\ University of Vienna; and ${ }^{3}$ Department of Psychology, University of Konstanz
}

\begin{abstract}
Both abnormal stress and reward responsivity are consistently linked to multiple forms of psychopathology; however, the nature of the associations between stress and reward sensitivity remains poorly understood. In the present study, we examined associations between the hypothalamic-pituitary-adrenal-axis stress response and event-related potentials sensitive to the receipt of reward-related feedback in a pre-post experimental paradigm. Neural responses were recorded while male participants completed a simple monetary-reward guessing task before and after the Montreal Imaging Stress Task. Results demonstrated that acute psychosocial stress significantly reduced the magnitude of neural responses to feedback in the reward-sensitive delta-frequency band but not the loss-sensitive theta-frequency band. In addition, a larger delta-frequency response to rewards at baseline predicted reduced overall cortisol response in the stress condition. These findings suggest, therefore, that neural reward circuitry may be associated with both risk for and resilience to stress-related psychopathology.
\end{abstract}

\section{Keywords}

psychophysiology, rewards, stress, open data

Received 7/10/19; Revision accepted 1/16/20

Life stress has been robustly linked to the onset and maintenance of mental illness (Andersen \& Teicher, 2009; Hammen, 1991, 2006; R. T. Liu \& Alloy, 2010; Monroe \& Harkness, 2005; Myin-Germeys, van Os, Schwartz, Stone, \& Delespaul, 2001; Post, 1992; Van Winkel, Stefanis, \& Myin-Germeys, 2008). Many different mechanisms are discussed by which stress contributes to an increased risk for mental illness; one such mechanism might be an inability to derive pleasure from formerly satisfying activities, also known as anhedonia (American Psychiatric Association, 2013). Stress is associated in both animals and humans with anhedonia, and anhedonia is a symptom characteristic of multiple forms of psychopathology, including depression (Pizzagalli, 2014; Proudfit, 2015; Whitton, Treadway, \& Pizzagalli, 2015), substance use (Baskin-Sommers \& Foti, 2015; Dawe, Gullo, \& Loxton, 2004; Kollins, 2003; Noble, 2000), psychosis (Radua et al., 2015; Strauss, Waltz, \& Gold, 2013), and posttraumatic stress disorder (PTSD; Frewen, Dozois, \& Lanius, 2012; Kashdan, Elhai, \& Frueh, 2006; Nawijn et al., 2015). This stress-induced loss of pleasure suggests that interactions between stress and neural-reward circuitry might contribute to a better understanding of the development of some forms of psychopathology (e.g., Pizzagalli, 2014).

Consistent with this theory, an accumulating body of evidence has demonstrated that stress is associated with decreased sensitivity to rewards measured by selfreport, behavior, and neural responses (Admon et al.,

\section{Corresponding Author:}

Anna Weinberg, McGill University, Department of Psychology, 2001

McGill College Ave., Montreal, Quebec, H3A 1G1

E-mail: anna.weinberg@mcgill.ca 
2013; Berenbaum \& Connelly, 1993; Berghorst, Bogdan, Frank, \& Pizzagalli, 2013; Boecker et al., 2014; Bogdan \& Pizzagalli, 2006; Casement et al., 2014; Dillon et al., 2009; Guyer et al., 2006; Kumar et al., 2014; W.-h. Liu et al., 2011; Mehta et al., 2010; Ossewaarde et al., 2011; Pizzagalli, Bogdan, Ratner, \& Jahn, 2007; Porcelli, Lewis, \& Delgado, 2012). Although the precise mechanisms underlying these associations are not fully understood (Hollon, Burgeno, \& Phillips, 2015), preclinical and human studies have suggested that both stress responses and reward processing involve activation of overlapping brain structures that are influenced by dopamine neurons in the ventral tegmental area (Cabib \& PuglisiAllegra, 2012; Pizzagalli, 2014; Sesack \& Grace, 2010). Moreover, exogenous administration of the hormone cortisol, which is released by the hypothalamic-pituitaryadrenal (HPA) axis in response to diverse stressors (Dickerson \& Kemeny, 2004), has been shown to blunt responses in reward-related neural circuitry (Kinner, Wolf, \& Merz, 2016), which points to a neurochemical connection between stress and reward processing.

However, a blunting effect of stress on reward processing is not consistently observed (e.g., Kumar et al., 2014; Lighthall et al., 2012; Lighthall, Gorlick, Schoeke, Frank, \& Mather, 2013; Mather \& Lighthall, 2012; Petzold, Plessow, Goschke, \& Kirschbaum, 2010), which suggests that additional mechanisms are at play linking stress and reward processing. Furthermore, although much of the work investigating stress and reward associations has examined whether the experience of stress drives a subsequently blunted neural response to rewards (Banis, Geerligs, \& Lorist, 2014; Banis \& Lorist, 2012; Berghorst et al., 2013; Kumar et al., 2014; Ossewaarde et al., 2011; Porcelli et al., 2012), a growing body of work has also aimed to identify whether enhanced prestressor functioning of reward-related neural circuitry may confer resistance to or enhance coping with stress (Cabib \& Puglisi-Allegra, 2012; Heller et al., 2013; Krishnan et al., 2007; Pegg et al., 2019; Sandre, Bagot, \& Weinberg, 2019; Tashjian \& Galván, 2018; Vidal-Ribas et al., 2019). For example, Heller and colleagues (2013) found that sustained activity to positive stimuli in the striatum and dorsolateral prefrontal cortex was associated with greater self-reported well-being and lower basal cortisol levels. Relatedly, evidence indicates that brain structures implicated in reward responding, including the prefrontal cortex, hippocampus, and amygdala, are involved in regulating cortisol reactivity in response to stress (Dedovic, Duchesne, Andrews, Engert, \& Pruessner, 2009). It appears critical, therefore, to not only consider how stress is associated with changes is reward responsiveness but also how reward sensitivity may influence stress responsiveness.

In humans, much of the research investigating associations between stress and reward processing has relied on retrospective self-reports of stress or has used stress as a prospective predictor of reward processing, without baseline measurements of neural responses to rewards (Birn, Roeber, \& Pollak, 2017; Casement et al., 2014; Ethridge, Sandre, Dirks, \& Weinberg, 2018; Hanson, Albert, et al., 2015; Kumar et al., 2015). Although these studies tend to demonstrate excellent ecological validity, they are correlational and so are necessarily limited in their ability to test directionality of effects. In other words, it is possible that those who experience increased stress have subsequently altered reward processing, but it is also possible that those with altered reward processing experience increased stress (Mackin et al., 2019). Implementing laboratory stress, however, allows for randomization of participants to stress and control groups and for measuring reward processing before and after stress induction. Together, these characteristics support the investigation of causal effects of stress on neural processes as well as the study of possible buffering effects of neural processes on stress responses.

A number of studies have demonstrated that an acute laboratory stressor is associated with reduced reward learning (Bogdan \& Pizzagalli, 2006; Bogdan, Santesso, Fagerness, Perlis, \& Pizzagalli, 2011; Morris \& Rottenberg, 2015; Starcke, Wolf, Markowitsch, \& Brand, 2008) as well as reduced neural response to rewards (Banis et al., 2014; Banis \& Lorist, 2017; Born et al., 2010; Gaffrey et al., 2018; Kumar et al., 2014; Lighthall et al., 2012; Ossewaarde et al., 2011; Porcelli et al., 2012; Treadway et al., 2017). Porcelli and colleagues (2012), for instance, found that for participants in the control condition, activation in the dorsal striatum and orbitofrontal cortex differentiated rewards and punishments, but this differentiation was not found for participants who experienced acute stress. Although cortisol responses significantly differed between the stress and control groups in this study, the authors did not find any significant associations between cortisol response and neural responses, as might be expected given previous evidence (Kinner et al., 2016).

It is possible that this lack of association between HPA-axis functioning and neural responses to rewards is due to the nature of the stressor used in the study. Specifically, Porcelli and colleagues (2012) used an MRI-compatible version of the cold pressor test, which involves a temperature manipulation; yet for a comprehensive investigation of the interaction between stress and reward systems, it might be preferable to employ stressors that involve limbic-system structures in the activation of the HPA axis rather than brain-stem structures (Dickerson \& Kemeny, 2004; Herman et al., 2003; Schwabe, Haddad, \& Schachinger, 2008). This may similarly be a limitation of other related studies (Banis et al., 
2014; Banis \& Lorist, 2017). Moreover, in several of these studies, researchers have manipulated stress using designs that precluded any test of whether baseline reward sensitivity might predict the HPA-axis stress response (Gaffrey et al., 2018; Lighthall et al., 2012; Ossewaarde et al., 2011; Porcelli et al., 2012), which highlights the need for studies using pre-post experimental designs. Although this growing body of research is promising, additional work is needed to replicate these findings and further clarify the nature of the associations among acute stress, HPA-axis functioning, and neural responses to rewards.

Interest in examining associations between stress and reward processing is largely motivated by efforts to identify mechanisms implicated in the development and course of psychopathology; thus, some initial work has assessed these associations in relation to clinical symptoms and in clinical populations (Casement et al., 2014; Hanson, Hariri, \& Williamson, 2015; Hanson, Knodt, Brigidi, \& Hariri, 2018; Kumar et al., 2015; Morris \& Rottenberg, 2015; Pegg et al., 2019). For example, Hanson, Hariri, and Williamson (2015) found that decreased reward-related ventral-striatum activity partially mediated the association between life stress and depressive symptoms in a sample of adolescents. Although this growing body of work supports the notion that neural response to rewards plays an important role in the link between stress and psychopathology, the correlational nature of these studies makes it difficult to infer causation. In addition, none of these studies examined biological stress responses, and thus, the direction of associations between HPA-axis (e.g., cortisol) response and neural reward response remains an open question. It is necessary, therefore, to further study the basic interactions among stress, HPA-axis functioning, and neural response to rewards to then be better equipped to investigate possible mechanistic roles that these processes play in the course of psychopathology.

Toward this end, in the present study, we sought to assess the associations between responses to a psychosocial stressor induced in the laboratory, as measured by cortisol, and neural response to rewards, as measured by electroencephalogram (EEG). The specific measure of reward processing used in this study was the event-related potential (ERP) commonly referred to as the reward positivity (RewP). The RewP is a positive deflection in the ERP waveform that is larger (more positive) for rewards than for nonrewards; the component is maximal approximately $300 \mathrm{~ms}$ after rewardrelated feedback at frontocentral recording sites on the scalp (Proudfit, 2015). Note that the RewP has been linked to activation in the striatum (Foti, Weinberg, Bernat, \& Proudfit, 2015) and to genes governing the regulation of dopamine (Foti \& Hajcak, 2012). However,
ERPs represent multiple cognitive, affective, sensory, and motor processes overlapping in time, and increasing evidence suggests that empirically decomposing ERPs into distinct underlying components (e.g., using time-frequency decompositions) may be of experimental and clinical value (for review, see Weinberg, Ethridge, Ait Oumeziane, \& Foti, in press).

Neural activity occurring in the time window of the RewP is thought to be composed of both deltafrequency $(\sim 1-4 \mathrm{~Hz})$ and theta-frequency $(\sim 4-8 \mathrm{~Hz})$ activity. Evidence suggests that delta power is increased after rewards, or positive outcomes, compared with losses or negative outcomes, whereas theta power appears specifically enhanced after nonrewards, or negative outcomes (Banis et al., 2014; Bernat, Nelson, \& Baskin-Sommers, 2015; Bernat, Nelson, Steele, Gehring, \& Patrick, 2011; Bowers, Buzzell, Bernat, Fox, \& Barker, 2018; Cohen, Elger, \& Ranganath, 2007; Foti et al., 2015; Van de Vijver, Ridderinkhof, \& Cohen, 2011; Webb et al., 2017). In addition, findings from source analyses indicate that delta and theta activity may have distinct neural generators: Gain-related delta has been localized to the striatum, whereas loss-related theta activity has been localized to the anterior cingulate cortex (Foti et al., 2015). Time-frequency decompositions of ERP data and evaluations of delta and theta activity in particular may therefore fruitfully add to the understanding of associations between stress and neural reward processing (Banis et al., 2014; Banis \& Lorist, 2017; Bernat et al., 2015; Bowers et al., 2018; Foti et al., 2015). Thus, in the present study, we sought to assess the associations among an acute psychosocial stressor induced in the laboratory, cortisol, and reward-related neural processes using time-frequency decompositions of the RewP and examining both delta and theta activity.

Specifically, we used a between- and within-participants design to address three primary aims: (a) to determine whether presence of an acute stressor degraded neural responses to reward-related feedback, (b) to determine whether acute stress demonstrated distinct effects on different frequencies of neuroelectric activity, and (c) to determine whether a robust neural reward response protected against stress-induced physiological arousal, as measured by salivary cortisol. Given previous evidence suggesting that stress is associated with impaired reward processing (e.g., Banis et al., 2014; Berenbaum \& Connelly, 1993; Berghorst et al., 2013; Bogdan \& Pizzagalli, 2006), we predicted that the induction of an acute psychosocial stressor in the laboratory would lead to a blunted RewP. We also predicted that heightened sensitivity to reward at baseline would be associated with reduced reactivity to stress, as measured by cortisol secretion, over the course of the stressor (Dedovic, Duchesne, et al., 2009; Heller et al., 2013). 


\section{Method}

\section{Participants}

One hundred twelve men were recruited from McGill University and the surrounding community using online and print advertisements and were randomly assigned to the experimental (i.e., stress) and control groups. Menstrual phase (Duchesne \& Pruessner, 2013; Maki et al., 2015; Villada et al., 2014) and hormonal contraceptive use (Roche, King, Cohoon, \& Lovallo, 2013) have been shown to strongly influence physiological indices of stress responses; thus, only men were included in this initial study to test the feasibility of the protocol and increase power for the primary analyses. Four participants were excluded because they did not complete the entire experimental paradigm, three were excluded because they reported use of psychotropic medications, two were excluded because of experimenter error, one control participant was excluded because he self-reported a high stress level during the control condition of the Montreal Imaging Stress Task (MIST), one stress participant was excluded because he self-reported no stress during the experimental condition of the MIST, and one participant was excluded because he selected "prefer not to answer" for the gender demographics question (similar to the approach chosen by Dedovic, Wadiwalla, Engert, \& Pruessner, 2009). Of the 100 participants included in the study ( 54 control, 46 stress), mean age was 21.93 years $(S D=$ 3.54 , range $=18-34$ years), and age did not differ among conditions, $t(96)=-0.29, p=.77,95 \% \mathrm{CI}=[-1.65,1.22]$. Fifty-five percent of the sample identified as White, 10\% identified as South Asian, 7\% identified as Arab/West Asian, 6\% identified as Chinese, 5\% identified as Southeast Asian, 3\% identified as Korean, 1\% identified as African American, 1\% identified as Hispanic, 1\% preferred not to answer, and 10\% identified as another ethnicity. Of the participants who responded to the question, "What is your approximate family income?" $33 \%$ reported income less than $\$ 50,000,21 \%$ reported income between $\$ 50,000$ and $\$ 99,999$, and $46 \%$ reported income of $\$ 100,000$ or more; however, $19 \%$ of the sample did not provide a response to this question. Demographic data were missing from two participants because they did not complete the demographic questionnaire.

\section{Procedure}

Participants provided written informed consent to complete a series of computer tasks while continuous EEG was recorded and to provide a series of salivary cortisol samples throughout the experiment. Participants began the computer tasks by completing the doors and flanker tasks (counterbalanced); this was followed by the first portion of the MIST, which was interrupted by an experimenter who, in the stress condition, observed the second portion of the MIST; participants then again completed the doors task, followed by the flanker task-these latter two tasks were not counterbalanced. All tasks were completed on an Intel Core i7 computer. Testing sessions were $2 \mathrm{hr}$, and sessions started between 9:00 a.m. and 4:00 p.m. Detailed descriptions of the tasks are provided below, and a depiction of the experimental paradigm is provided in Figure 1a. In addition, before debriefing, participants were asked to rate on a scale from 1 (not at all) to 5 (extremely) how stressed they felt during MIST 2, and their response was recorded by an experimenter. Participants received course credit or CAD $\$ 20.00$ for their participation in the study, in addition to $\$ 3.00$ in winnings from the two doors tasks. McGill University's Research Ethics Board approved all procedures.

\section{Tasks}

Doors. The doors task is commonly used to elicit neural responses to reward-related feedback (Proudfit, 2015). In this task, participants viewed two doors on a screen and were asked to guess which of the two doors was hiding a prize by clicking the left or right mouse button. After their selection, participants either saw a green arrow pointing up, which indicated that they had chosen correctly and had won $\$ 0.50$ on that trial (i.e., gain), or they saw a red arrow pointing down, which indicated that they had chosen incorrectly and had lost $\$ 0.25$ on that trial (i.e., loss). Gain and loss feedback were each presented on $50 \%$ of trials in random order. A trial sequence is depicted in Figure 1b; the version of the task used in this study consisted of two blocks of 15 trials. Before beginning the task, participants were informed that they could win up to $\$ 5.00$ during the task, and their winnings were given to them immediately after completing the task. All participants received $\$ 2.00$ after completing Doors 1 and $\$ 1.00$ after completing Doors 2. The task was presented using Presentation software (Version 18.1, Neurobehavioral Systems, Inc., Berkeley, CA). This task has been shown to elicit reward-related ERPs with good internal consistency reliability and good test-retest reliability (Bress, Meyer, \& Proudfit, 2015; Ethridge \& Weinberg, 2018; Levinson, Speed, Infantolino, \& Hajcak, 2017; Luking, Nelson, Infantolino, Sauder, \& Hajcak, 2017).

Flanker. The flanker task is commonly used to measure neural responses to making mistakes (Eriksen \& Eriksen, 1974). The version of the task used in this study involved seeing a horizontal array of arrows on a computer screen (e.g., " $<<><<$ ") and quickly and accurately identifying the direction of the center arrow using the mouse buttons. 

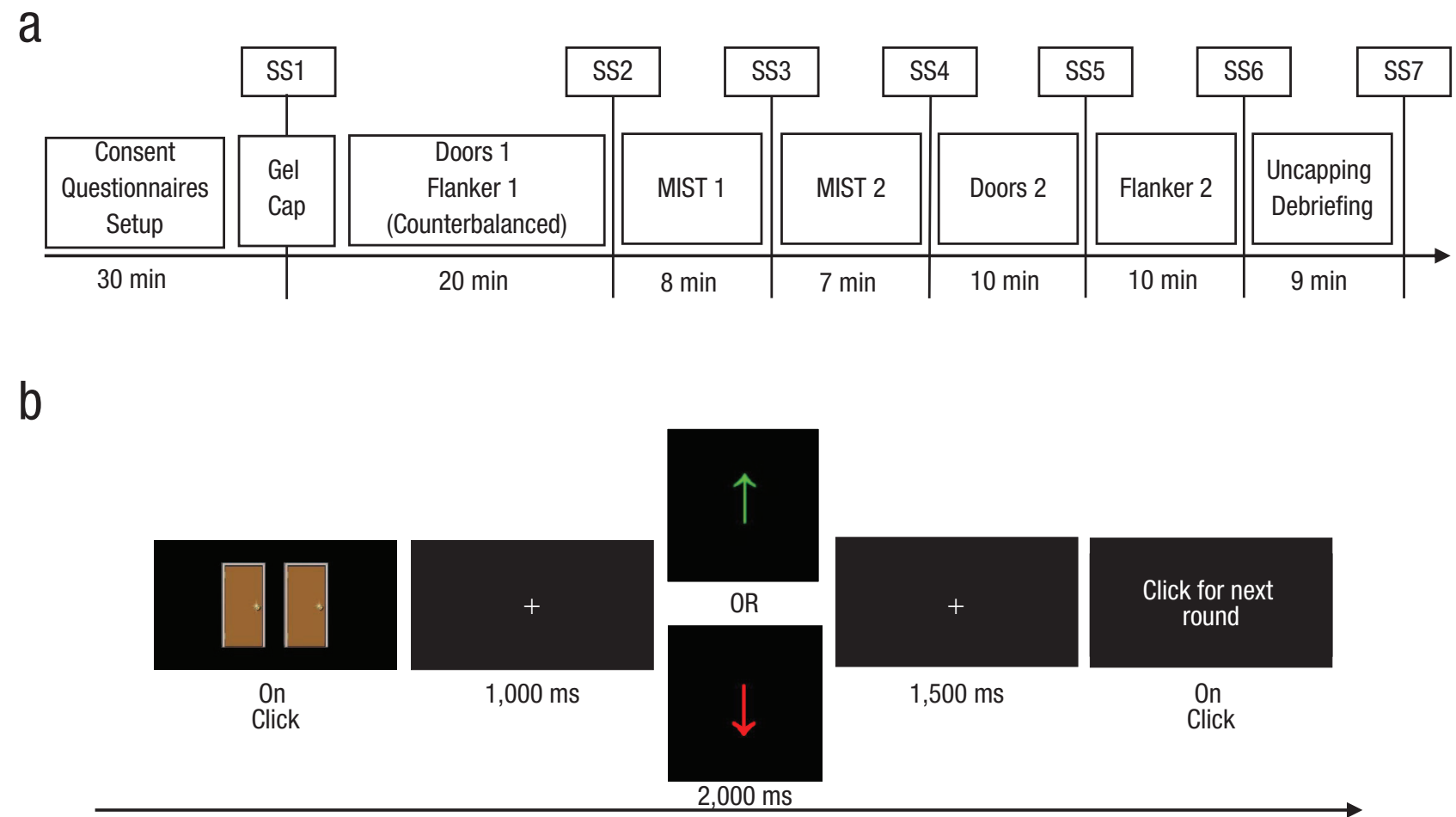

C

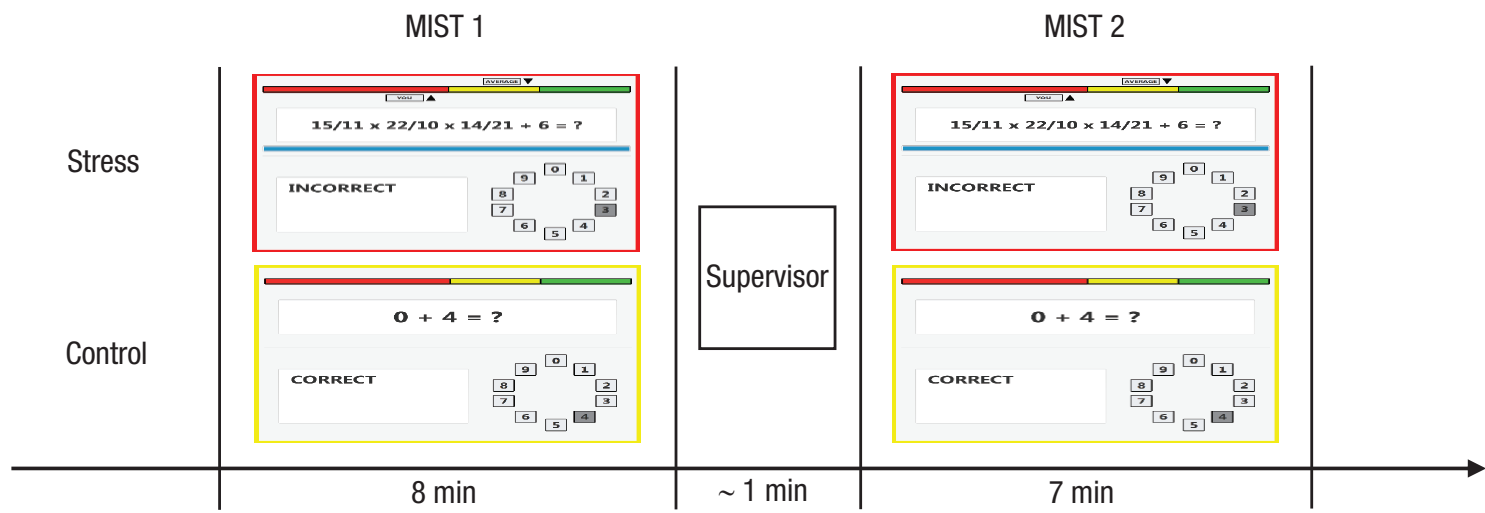

Fig. 1. Timeline of the laboratory visit (a), a trial in the doors task (b), and the Montreal Imaging Stress Task (MIST) paradigm, including MIST 1 and MIST 2 (c). In (a), "SS" indicates that a saliva sample was provided. Shown in (c) are examples of the task and task sequence for MIST 1 and MIST 2. Note that the supervisor entered the testing room between MIST 1 and MIST 2 in both conditions, but the supervisor remained in the testing room for the duration of MIST 2 in the stress condition.

Because the primary aim of this study was to examine associations between stress and reward processing, data from this task are reported in the Supplemental Material available online.

MIST. The MIST is a task designed to use computerized mental arithmetic challenges and social evaluation to induce a physiological and endocrine stress response (Dedovic et al., 2005; see Fig. 1c). In the stress condition, each MIST trial was time-limited, which was indicated by a blue progress bar that moved from left to right on the computer screen and an aversive beeping sound that increased in pitch across each trial. To provide an answer, participants navigated to their intended choice using numbers " 1 " to " 3 " on the number pad on the keyboard, which operated a rotary dial shown on the bottom right side of the computer screen (choosing "1" moved the dial counterclockwise, choosing " 3 " moved the dial clockwise, and choosing "2" confirmed the current number as the designated answer). If participants chose correctly, "correct" appeared on the screen; if they chose incorrectly or did not respond within the time limit, "incorrect" 
appeared on the screen. Depending on participants' performance on previous trials, the difficulty of arithmetic questions and the time allowed to answer was adjusted to maintain a high failure rate (between about $55 \%$ to 80\% failure; see Dedovic et al., 2005, for a detailed description of task parameters). A performance indicator, which identified participant performance compared with a false "average" performance, appeared at the top of the screen; participants' performance was thus shown to be below this "average" in the experimental condition. In the control condition, equations were simpler, trials were not time-limited and were not accompanied by a beeping noise, and participants' performance compared with "average" was not indicated on the screen. In both conditions, a correct response was accompanied by a pleasant beep, and an incorrect response or no response was accompanied by an aversive buzzer.

After completing $8 \mathrm{~min}$ of the MIST, the task was terminated by an experimenter. In the stress condition, the experimenter informed the participant that there was a problem with his data and that they would need assistance from their supervisor. In the control condition, the experimenter informed the participant simply that they needed their supervisor to check something with the computer. The experimenter then retrieved another experimenter, with whom the participant had not yet interacted, who entered the testing room as the supervisor; supervisors were always women. In the stress condition, the supervisor maintained a neutral demeanor and asked the participant several questions, including if he understood the instructions to the task, if he had experience doing arithmetic (e.g., had ever taken a math class), and if he could see the computer screen properly. The supervisor then told the participant that his data could not be used if his performance was not at the "average" level. The supervisor began the program again and stood behind the participant while he completed the MIST a second time. After $7 \mathrm{~min}$, the supervisor told the participant that the performance was not adequate, terminated the task, and asked the experimenter to run the previous tasks (doors and flanker) again in order to obtain some usable data. In the control condition, the supervisor, while maintaining a cheerful and friendly demeanor, informed the participant that she had to check something on the computer but that there was nothing wrong with his data or his performance. The supervisor then pretended to check if the program was working properly. The supervisor informed the participant and the experimenter that everything was working well and instructed them to continue the MIST. The supervisor also instructed the experimenter to collect additional data from the initial tasks, purportedly because they would have some spare time left in the testing session. The supervisor then left the room, and the participant completed the three remaining tasks (MIST 2, Flanker 2, Doors 2).

\section{Psychophysiological recording, data reduction, and analysis}

Electroencephalogram. A 32-electrode BrainVision actiCHamp system (standard 10/20 layout; Brain Products, Munich Germany) was used to record continuous EEG throughout the computer tasks. A ground electrode was placed at Fpz, and to generate the electrooculogram (EOG), peripheral electrodes were placed $1 \mathrm{~cm}$ above and below one eye (VEO) and $1 \mathrm{~cm}$ from the outer canthi of each eye (HEO), and were referenced to an electrode on the back of the neck. Data were recorded with a sampling rate of $1000 \mathrm{~Hz}$. Electrode impedances were kept below $10 \mathrm{k} \Omega$. Processing of the data was completed offline using BrainVision Analyzer software (Brain Products, Munich, Germany). Data were band-pass filtered with low and high cutoffs of $0.01 \mathrm{~Hz}$ and $30 \mathrm{~Hz}(24 \mathrm{~dB} / \mathrm{oct})$, respectively, and were referenced to an average of TP9 and TP10 (left and right mastoids). Correction of ocular artifacts was then conducted using a modification of the algorithm published in Gratton, Coles, and Donchin (1983).

For time-domain analyses, data were initially segmented into 1,200-ms epochs, $200 \mathrm{~ms}$ before and 1,000 $\mathrm{ms}$ after presentation of gain or loss feedback. A semiautomatic artifact-rejection procedure was conducted in which artifacts were detected and rejected in individual channels when any of the following occurred: a voltage step greater than $50 \mu \mathrm{V} / \mathrm{ms}$, a change of 175 $\mu \mathrm{V}$ within $400 \mathrm{~ms}$, or activity of less than $0.5 \mu \mathrm{V}$ within $100 \mathrm{~ms}$. Remaining artifacts were then rejected via visual inspection of the data. Data from gain and loss trials were averaged separately; activity in the $200 \mathrm{~ms}$ before feedback onset was used for baseline correction. The RewP was scored 230 to $330 \mathrm{~ms}$ after gain or loss feedback using an average of the activity at Fz, Cz, FC1, and FC2 (hereafter referred to as the frontocentral average, or $\mathrm{FC}_{\text {avg }}$ ). To calculate split-half reliability of the ERPs, odd and even trials were also averaged separately for gain and loss feedback. ERPs quantified at $\mathrm{FC}_{\text {avg }} 230$ to $330 \mathrm{~ms}$ after feedback at both time points and for both feedback types demonstrated acceptable split-half reliability (corrected using the Spearman-Brown prophecy formula; Doors 1 gain: $r=.89$; Doors 1 loss: $r=$ .85; Doors 2 gain: $r=.81$; Doors 2 loss: $r=.83$ ).

For time-frequency analyses, data were resegmented into 2,500-ms-epochs, $1,000 \mathrm{~ms}$ before and 1,500 ms after feedback onset. The same parameters were used for mastoid referencing and ocular correction as in the time-domain-scored data. An automatic artifact-rejection procedure was conducted in which data from individual channels were rejected if there was a voltage step 
greater than $30 \mu \mathrm{V} / \mathrm{ms}$, a difference greater than 150 $\mu \mathrm{V}$ within $200 \mathrm{~ms}$, an amplitude less than $-125 \mu \mathrm{V}$ or greater than $125 \mu \mathrm{V}$, or activity of less than $0.5 \mu \mathrm{V}$ in 100 -ms intervals. Gain and loss trials were again averaged separately within participants, and activity in the $200 \mathrm{~ms}$ before feedback onset was used for baseline correction. ${ }^{1}$ A continuous wavelet transform using the Morlet complex was calculated with a minimal frequency of 0.01 and a maximum frequency of 20, 20 frequency steps, a Morlet parameter c of 5, and Gabor normalization. Finally, for each feedback type, layers were extracted corresponding to the delta- and thetafrequency bands. The delta band had a central frequency of $2.71 \mathrm{~Hz}$ (spectral bandwidth: $1.08 \mathrm{~Hz}$ ), and the theta band had a central frequency of $6.02 \mathrm{~Hz}$ (spectral bandwidth: $2.41 \mathrm{~Hz}$ ). These data were analyzed between 200 and $400 \mathrm{~ms}$ after feedback onset at $\mathrm{FC}_{\mathrm{avg}}$.

Salivary cortisol. Beginning $30 \mathrm{~min}$ after participants arrived in the lab, saliva cortisol samples were collected at seven time points throughout the study visit at 7- to 20-min intervals (Fig. 1a) using the Salivette Collection Device (Starstedt, Inc., Numbrecht, Germany). Participants placed the saliva collection swabs in their mouths and were instructed to refrain from chewing for $2 \mathrm{~min}$. After 2 min, participants expelled the swab into a sterile tube using their tongues. Cortisol samples were assayed at the Biochemical Lab in the Department of Biological and Clinical Psychology at the University of Trier (Trier, Germany) using a time-resolved fluorescence immunoassay (Dressendörfer, Kirschbaum, Rohde, Stahl, \& Strasburger, 1992). All samples were assayed twice, and all cortisol analyses used the mean value. The average intraassay coefficient of variation for each sample was $4.86 \%(S D=3.82$; Kirschbaum \& Hellhammer, 2000).

\section{Data analysis}

Analyses were conducted using IBM SPSS (Version 21). To determine the effectiveness of the stress manipulation, differences between conditions in subjective stress ratings and salivary cortisol were examined. First, an independent-samples $t$ test was conducted to compare subjective stress ratings between the groups. In addition, we calculated the proportion of participants in the stress group who could be considered as having demonstrated a cortisol response, conservatively defined by a $2.5 \mathrm{nmol} / \mathrm{L}$ increase in salivary cortisol over baseline levels (calculated for each participant individually; Miller, Plessow, Kirschbaum, \& Stalder, 2013), to determine whether our implementation of the MIST was as effective in eliciting a physiological stress response as other similar laboratory stress paradigms.

Next, mixed-design repeated measures analyses of variance (ANOVAs) were conducted to determine if there were differences in the gain and loss responses between Doors 1 and Doors 2 across the groups for the time-domain-scored and the time-frequency-scored ERP data. Each of these three analyses was designed as a 2 (Feedback: loss vs. gain) $\times 2$ (Time: Time 1 vs. Time 2) $\times 2$ (Condition: stress vs. control) ANOVA. Effect sizes for ANOVAs were calculated as partial $\eta^{2}$ $\left(S S_{\text {effect }} /\left(S S_{\text {effect }}+S S_{\text {error }}\right)\right)$. Post hoc $t$ tests were conducted to determine the nature of significant interactions and are presented with 95\% confidence intervals (CIs). The significance level for all statistical tests was set at $p<.05$ (two-tailed).

Cortisol trajectories were then modeled using multilevel modeling with maximum likelihood estimation using the SPSS linear mixed models procedure. Multilevel modeling (MLM) allowed for the prediction of within-participant differences in physiological response to stress, accounting for the correlated natured of repeated measures data by adjusting standard errors of regression coefficients and permitting retention of individuals who were missing cortisol values at one or more time points (Singer, Willett, \& Willett, 2003). Models were built using the strategy recommended by Bryk and Raudenbush (1987). Specifically, separate two-level models were fit to predict cortisol trajectories for individuals in the stress group and individuals in the control group. Level 1 of each model represented intraindividual differences in cortisol as predicted by time. Level 2 of each model represented interindividual effects (i.e., neural responses to feedback at Time 1: Time 1 delta power 200-400 ms after gain or loss feedback at $\mathrm{FC}_{\text {avg }}$ or Time 1 theta power 200-400 ms after gain or loss feedback at $\mathrm{FC}_{\mathrm{avg}}$ ) on the intercept and the slopes of the outcome variable.

To model the linear trajectory of cortisol level in our samples, time points that captured reactivity to the MIST task were used. The initial saliva samples (SS; SS1, SS2, and SS3 in Figs. $1 \mathrm{a}$ and 2b) were not included in the cortisol analyses because these samples are likely noisy measures, due to participants having just arrived in the lab and undergone EEG capping and gelling. Moreover, it is typical to include a waiting period after arriving in the lab before inducing stress (Ali, Nitschke, Cooperman, \& Pruessner, 2017; Pruessner et al., 2008), and we were primarily interested in associations between baseline reward response and cortisol reactivity to stress. Therefore, the first sample after the stressor in the stress condition (SS4) and all subsequent saliva samples were entered into the models for both groups. Time was centered at the first time included in analyses (SS4). We then tested the effect of age, time, neural responses (i.e., delta responses to gains and losses; theta responses to gains and losses), the Delta Gain $\times$ Time Interaction, and the Theta Loss $\times$ Time interaction on cortisol responses. Age information was missing for two participants in the 
stress condition, so the sample for the stress group in this analysis was 44 . We focused on delta-gain and theta-loss activity in the interactions with time given evidence that activity in the delta and theta frequencies are most sensitive to gain and loss feedback, respectively (Bernat et al., 2015; Foti et al., 2015). On the basis of log-likelihood ratio difference tests, the best fitting model had unstructured covariance matrices and intercepts and slopes that were allowed to vary randomly. EEG variables were standardized before the MLM analysis, and so coefficients for these independent variables are presented as estimates of effect size. Finally, post hoc $t$ tests were conducted to determine the time points at which salivary cortisol measurements differed between groups; 95\% CIs are presented with all $t$ tests.

\section{Results}

\section{Manipulation check and random assignment}

Comparisons of the stress and control groups on multiple measures confirmed random assignment by showing no significant differences between conditions on session start time or baseline cortisol, $p \mathrm{~s}>.19$. Subjective ratings of stress experienced during the second portion of the MIST task (i.e., during supervisor observation for the stress group, given that this was expected to be the most stressful portion of the task) were significantly different across groups, $t(73.87)=-11.05$, $p<.001,95 \% \mathrm{CI}=[-2.28,-1.58]$ (corrected for unequal variances); the participants in the stress condition rated higher subjective stress $(M=3.37, S E M=0.15)$ than those in the control condition $(M=1.44, S E M=$ 0.09).

Figure 2 depicts the impact of the stress manipulation on (a) subjective stress ratings and (b) cortisol. Forty-four percent of participants in the stress condition demonstrated a cortisol response to the stressor, which is slightly below studies using the "gold standard" laboratory stress manipulation, the Trier Social Stress Test (e.g., Engert et al., 2013; Kudielka, Kirschbaum, \& Hellhammer, 2007) but is similar to studies involving laboratory stress manipulations in imaging contexts (e.g., Dierolf, Fechtner, Bohnke, Wolf, \& Naumann, 2017; Pruessner et al., 2008). However, note that we may not have captured the peak cortisol response in this sample (i.e., cortisol may have continued to increase beyond SS7; see Fig. $2 \mathrm{~b}$ ) and that $2.5 \mathrm{nmol} / \mathrm{L}$ may be an overly conservative threshold (Miller et al., 2013); therefore, the percentage of participants who demonstrated a cortisol response reported here may be an underestimation. Cortisol responders and nonresponders demonstrated a small numeric difference in their subjective stress ratings that was not significant, $t(44)=-1.99, p=.053,95 \%$ $\mathrm{CI}=[-1.18,0.007]$ (responders: $M=3.70$, SEM $=0.21$; nonresponders: $M=3.12$, SEM $=0.20$ ). a

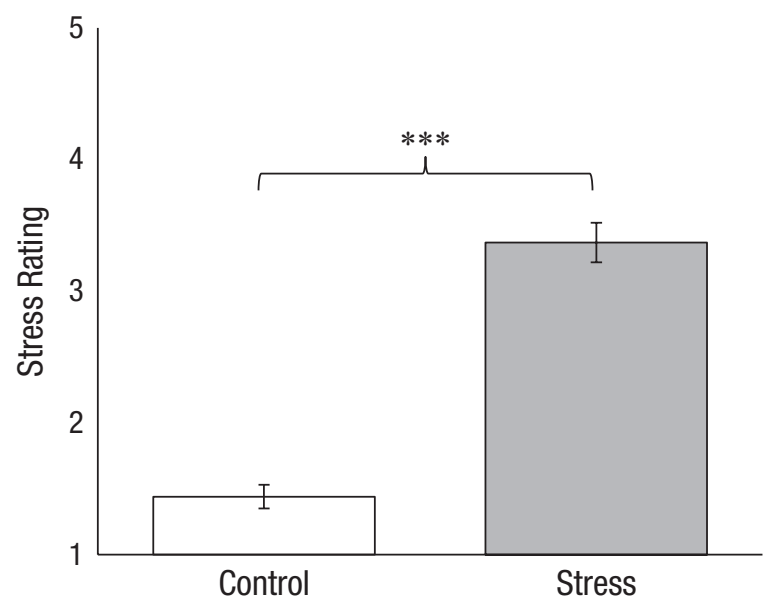

b

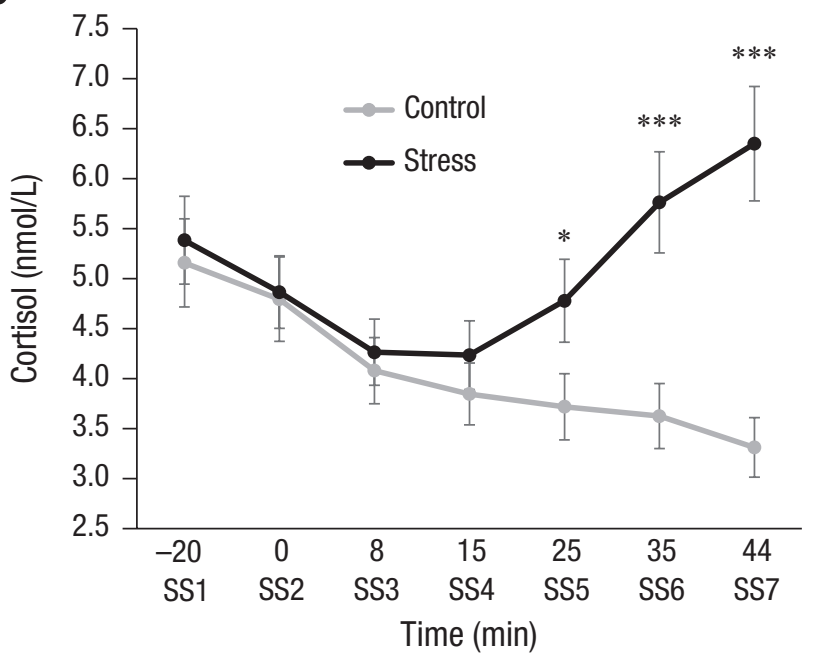

C

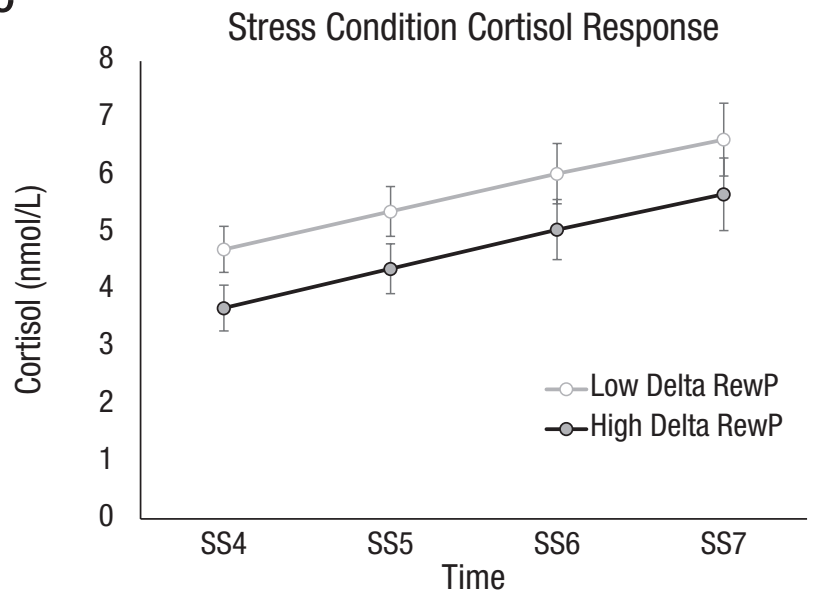

Fig. 2. Self-report and cortisol measurements describing responsiveness to the experimental manipulation. Subjective stress ratings (a) are shown for the control and stress conditions after completion of the experimental paradigm. Salivary cortisol measurements (b) are presented for each saliva sample (SS), separately for the control and stress conditions. Error bars represent standard error of the mean. Salivary cortisol measurements are graphed (c) for SS4 through SS7 for participants in the stress condition on the basis of the 25th percentile (low delta activity in the time window of the Reward Positivity, or RewP) and 75th percentile (high delta activity in the time window of the RewP) values for standardized delta-frequency response to reward during Doors 1 . Asterisks indicate significant differences between conditions $(* p \leq .05, * * p \leq .001)$. 


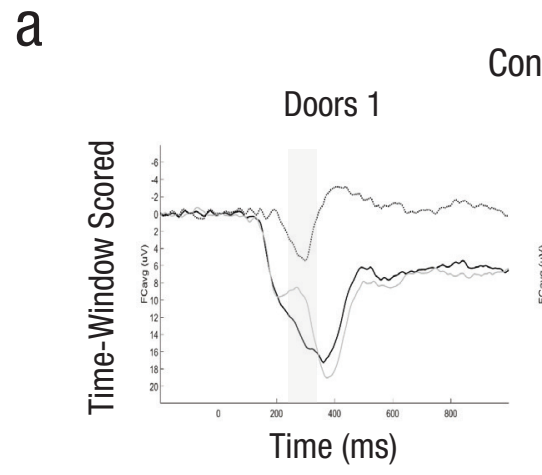

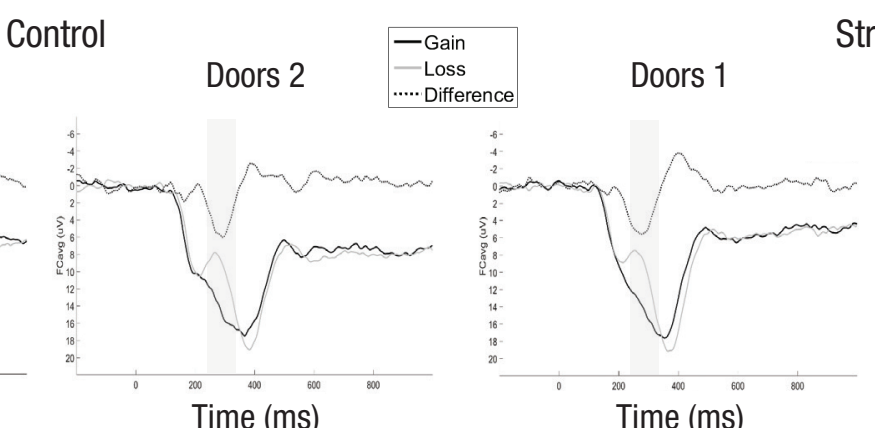

Time (ms)
Stress

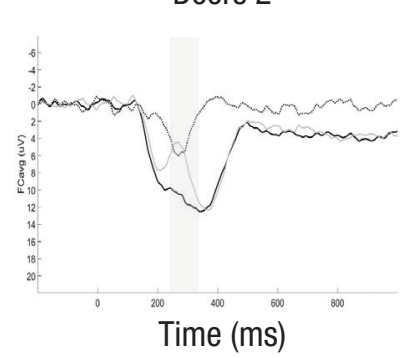

Stress

b

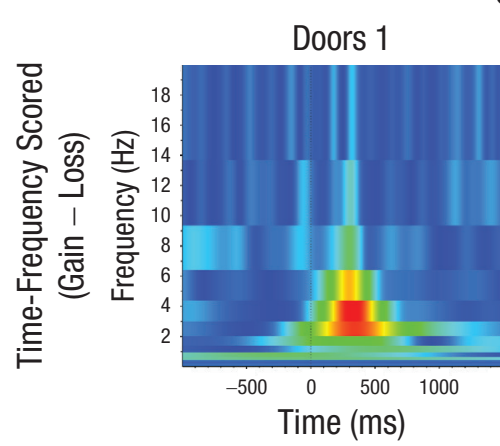

Control
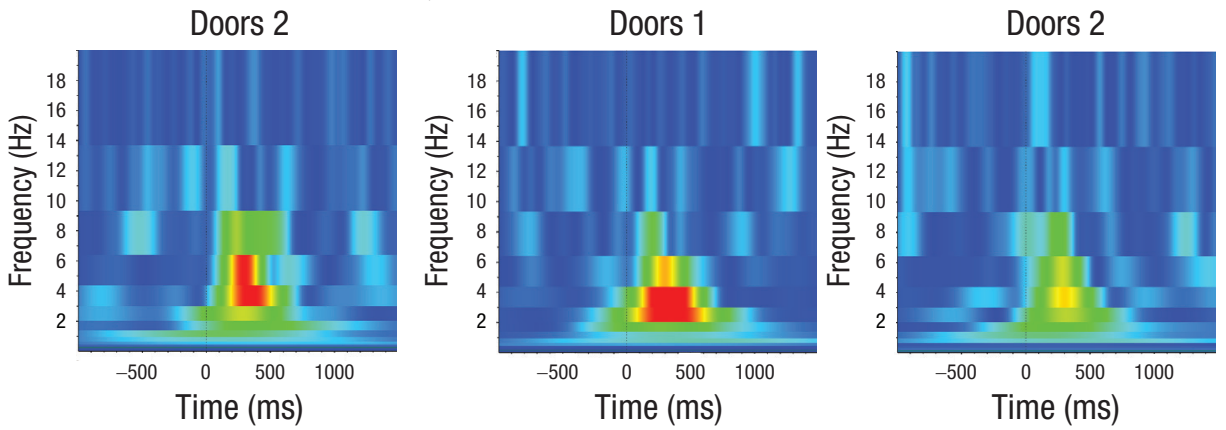

Fig. 3. Event-related potential (ERP) waveforms for the time-domain-scored data (a) and plots of the time-frequency-scored data (b) for the stress and control groups at Time 1 (pre-MIST) and Time 2 (post-MIST) of the doors task. The "Difference" line in the ERP waveforms was calculated as gain minus loss. Likewise, the time-frequency plots depict the difference in power (gain trials minus loss trials). MIST $=$ Montreal Imaging Stress Task.

\section{Impact of acute stress on EEG responses}

Time-domain amplitude. Waveforms representing the neural responses to gain and loss feedback for each group before and after the MIST are presented in Figure 3a. The ANOVA conducted on the time-domain-scored ERP data demonstrated the following: a main effect of feedback, $F(1,98)=181.74, p<.001$, partial $\eta^{2}=.65$, in which the neural response to gain $(M=13.18$, SEM $=$ $0.55)$ was larger than the neural response to loss $(M=$ 8.92, SEM = 0.54); a main effect of time, $F(1,98)=19.98$, $p<.001$, partial $\eta^{2}=.17$, in which neural response at Doors $1(M=11.88, S E M=0.56)$ was larger than neural response at Doors $2(M=10.22, S E M=0.55)$; and a significant Time $\times$ Condition interaction, $F(1,98)=17.80$, $p<.001$, partial $\eta^{2}=.15$, in which there was a significant reduction in neural response from Doors 1 to Doors 2 in the stress condition (mean difference $=3.23, S E M=0.56$ ), $t(45)=5.76, p<.001,95 \% \mathrm{CI}=[2.10,4.36]$, but not in the control condition (mean difference $=0.09, S E M=0.49$ ), $t(53)=0.19, p=.85,95 \% \mathrm{CI}=[-0.90,1.08]$. We did not, however, find evidence of a significant Feedback $\times$ Condition interaction, $F(1,98)=0.20, p=.66$, partial $\eta^{2}=$ .002; a Feedback $\times$ Time interaction, $F(1,98)=0.13, p=$
.72 , partial $\eta^{2}=.001$; or a three-way Feedback $\times$ Time $\times$ Condition interaction, $F(1,98)=0.26, p=.61$, partial $\eta^{2}=$ .003 .

\section{Time-frequency amplitude.}

Delta. Findings from analysis of data in the delta-frequency band mirror results from the time-domain-scored data. We observed a main effect of feedback, $F(1,98)=36.67$, $p<.001$, partial $\eta^{2}=.25$, whereby gains elicited greater delta power (mean gain $=3.27, S E M=0.12)$ than losses (mean loss $=2.76, S E M=0.12$ ); a main effect of time, $F(1,98)=16.42, p<.001$, partial $\eta^{2}=.14$, whereby neural response at Doors $1(M=3.21, S E M=0.13)$ was larger than neural response at Doors $2(M=2.82$, SEM $=$ $0.12)$; and a Time $\times$ Condition interaction, $F(1,98)=19.08$, $p<.001$, partial $\eta^{2}=.16$ (Fig. 3b), in which there was a significant reduction in feedback-related delta power in the stress condition from Doors 1 to Doors 2 (mean difference $=0.81, S E M=0.16), t(45)=5.06, p<.001,95 \%$ $\mathrm{CI}=[0.49,1.13]$, but not in the control condition (mean difference $=-0.03, S E M=0.11), t(53)=-0.27, p=.79$, $95 \% \mathrm{CI}=[-0.26,0.20]$. We again did not find evidence of a significant Feedback $\times$ Condition interaction, $F(1$, 98) $=0.23, p=.63$, partial $\eta^{2}=.002$; a Feedback $\times$ Time interaction, $F(1,98)=2.05, p=.16$, partial $\eta^{2}=.02$; or a 
Table 1. Multilevel Modeling Tests of Fixed Effects for Delta and Theta Power From 200 to 400 ms After Reward and Loss Feedback Predicting Cortisol Responses to the Montreal Imaging Stress Task

\begin{tabular}{|c|c|c|c|c|c|c|}
\hline Variable & \multicolumn{3}{|c|}{ Control } & \multicolumn{3}{|c|}{ Stress } \\
\hline Age & $-0.03(0.08)$ & $-0.35(50.61)$ & {$[-0.20,0.14]$} & $-0.14(0.10)$ & $-1.42(45.64)$ & {$[-0.33,0.06]$} \\
\hline Time & $-0.12(0.05)$ & $-2.32(41.00)^{*}$ & {$[-0.23,-0.02]$} & $0.67(0.15)$ & $4.55(44.23)^{* * * * *}$ & {$[0.37,0.96]$} \\
\hline Delta response to gains & $0.02(0.39)$ & $0.06(53.71)$ & {$[-0.75,0.80]$} & $-0.96(0.44)$ & $-2.17(47.50)^{*}$ & {$[-1.85,-0.07]$} \\
\hline Theta response to losses & $0.68(0.47)$ & $1.45(53.66)$ & {$[-0.26,1.62]$} & $0.46(0.37)$ & $1.26(45.18)$ & {$[-0.28,1.21]$} \\
\hline Time $\times$ Delta Response to Gains & $-0.003(0.05)$ & $-0.06(40.42)$ & {$[-0.11,0.11]$} & $0.02(0.17)$ & $0.13(43.02)$ & {$[-0.33,0.37]$} \\
\hline Time $\times$ Theta Response to Losses & $-0.03(0.07)$ & $0.50(40.87)$ & {$[-0.10,0.17]$} & $-0.07(0.14)$ & $-0.52(41.33)$ & {$[-0.36,0.21]$} \\
\hline
\end{tabular}

Note: $\mathrm{CI}=$ confidence interval.

${ }^{*} p<.05 . *{ }^{*} p \leq .001$.

significant three-way Feedback $\times$ Time $\times$ Condition interaction, $F(1,98)=0.21, p=.65$, partial $\eta^{2}=.002$.

Theta. Analysis of data from the theta-frequency band, however, demonstrated a different pattern of results. A significant main effect of feedback was found, $F(1,98)=$ 88.91, $p<.001$, partial $\eta^{2}=.48$, in which the response was larger for loss feedback $(M=3.05$, SEM $=0.13)$ than for gain feedback $(M=1.99, S E M=0.10)$; however, no significant effects were present for time, $F(1,98)=3.76$, $p=.06$, partial $\eta^{2}=.04$; the Feedback $\times$ Condition interaction, $F(1,98)=0.65, p=.42$, partial $\eta^{2}=.01$; the Time $\times$ Condition interaction, $F(1,98)=2.25, p=.14$, partial $\eta^{2}=$ .02 ; the Feedback $\times$ Time interaction, $F(1,98)=0.01, p=$ .95 , partial $\eta^{2}=.00$; or the Feedback $\times$ Time $\times$ Condition interaction, $F(1,98)=0.64, p=.43$, partial $\eta^{2}=.01$.

\section{Impact of acute stress and neural response to rewards on cortisol}

Table 1 depicts the results of the two MLMs examining predictors of cortisol response in the experimental and control groups. As hypothesized, time was a significant predictor of cortisol response in the stress condition; cortisol levels increased in a linear fashion over time, $b=0.67, S E=0.15, t(44.23)=4.55, p<.001,95 \% \mathrm{CI}=$ $[0.37,0.96]$. Time was also a significant predictor of cortisol in the control condition; however, in the control condition, cortisol levels decreased in a linear fashion over time, $b=-0.12, S E=0.05, t(41.00)=-2.32, p=$ $.03,95 \% \mathrm{CI}=[-0.23,-0.02])$. Post hoc comparisons revealed that the difference in cortisol values between conditions was significant for SS5, $t(97)=-2.02, p=$ $.046,95 \% \mathrm{CI}=[-2.10,-0.02]$; SS6, $t(75.21)=-3.55, p=$ $.001,95 \% \mathrm{CI}=[-3.34,-0.94] ;$ and SS7, $t(60.91)=-4.72$, $p<.001,95 \% \mathrm{CI}=[-4.33,-1.75]$ (Levene's test $p \mathrm{~s}<.05$ for SS6 and SS7, so adjusted values are reported); the cortisol values were greater in the stress condition (SS5: $M=4.78$, SEM $=0.41 ;$ SS6: $M=5.76$, SEM $=0.51$; SS7: $M=6.35, S E M=0.57)$ than in the control condition (SS5: $M=3.72, S E M=0.33$; SS6: $M=3.62$, SEM $=0.33$; SS7: $M=3.31$, SEM = 0.30; Fig. 2b).

Contrary to our predictions, the magnitude of delta power after reward feedback did not significantly interact with time to predict cortisol levels in the stress condition. Instead, a larger neural response to rewards at baseline predicted lower levels of cortisol overall in the stress group, $b=-0.96, S E=0.44, t(47.50)=-2.17$, $p=.04,95 \% \mathrm{CI}=[-1.85,-0.07]$. To illustrate this effect, we plotted cortisol values for the 25 th and 75 th percentiles of the delta RewP during Doors 1 in the stress group in order to depict differences in cortisol responses after initiation of the MIST in those with high and low baseline neural sensitivity to reward (Fig. 2c). In contrast, neural response to rewards was not significantly associated with cortisol levels in the control group, $b=.02, S E=0.39, t(53.71)=0.06, p=.95,95 \% \mathrm{CI}=$ $[-0.75,0.80]$. Consistent with our predictions, there were no statistically significant main effects of theta power or interactions between theta power and time in the prediction of cortisol levels in either group (see Table 1). ${ }^{2}$

\section{Discussion}

A growing body of literature suggests that stress is associated with the brain's response to rewards (Banis \& Lorist, 2012; Berghorst et al., 2013; Ethridge, et al., 2018; Kumar et al., 2014; Porcelli et al., 2012) and that this association may be linked to the development of illnesses such as depression, substance use, psychosis, and PTSD (Baskin-Sommers \& Foti, 2015; Dawe et al., 2004; Kashdan et al., 2006; Nawijn et al., 2015; 
Pizzagalli, 2014; Radua et al., 2015; Whitton et al., 2015). In the present study, we sought to extend this literature by examining the effect of an acute psychosocial stressor on a sensitive measure of neural processing of rewards, the RewP, and its associated spectral characteristics, and by examining potential buffering effects of increased neural response to reward on HPAaxis response to the stressor. This study replicated previous work showing that delta power is specifically enhanced after reward-related feedback (Bernat et al., 2015; Bernat et al., 2011; Bowers et al., 2018; Webb et al., 2017) and further demonstrated that the previously identified reduction in reward-related neural activity after stress (e.g., Berghorst et al., 2013; Casement et al., 2014; Ethridge et al., 2018; Ossewaarde et al., 2011; Porcelli et al., 2012; Treadway, Buckholtz, \& Zald, 2013) was specific to neural activity in the delta frequency. Lastly, this study demonstrated that baseline reward sensitivity in the delta frequency was associated with a reduced cortisol response to a subsequent stressor. Taken together, these findings support the idea that stress and the brain's reward circuitry may have a bidirectional relationship that underlies pathways of risk and resilience for pathology (Vidal-Ribas et al., 2019).

However, we did not find that stress exhibited a specific effect on reward processing; rather, we found that, using a time-domain-scoring approach, neural responses to gains and losses were blunted after the stressor. Despite aforementioned evidence underscoring associations between stress and reward processing specifically (e.g., Berghorst et al., 2013; Porcelli et al., 2012), ours is not the first study to demonstrate nonspecific effects of stress (Banis et al., 2014; Treadway et al., 2013); for example, Treadway and colleagues (2013) reported that perceived stress over the previous month was associated with blunted activation in the medial prefrontal cortex after both reward and loss feedback. It is possible that inconsistencies in the literature have arisen as a result of methodological differences such as comparing reward and punishment with reward and other nonreward conditions (e.g., loss or no-outcome conditions), considering different types of stressors (e.g., chronic vs. acute), or using different reward paradigms (Berghorst et al., 2013; Ethridge et al., 2018; Kumar et al., 2014; Lincoln et al., 2019; Pegg et al., 2019; Porcelli et al., 2012; Treadway et al., 2013). Alternatively, the present findings are consistent with the body of work suggesting that anhedonia may be associated with reductions in both positive and negative reactivity (Bylsma, Morris, \& Rottenberg, 2008); that is, anhedonia may represent an overall reduction in the motivational salience of cues in the environment. It follows, then, that stress-induced anhedonia, as may be represented at the neural level in the present study, would be associated with blunted responses to both positive and negative feedback. Combined, these findings underscore the complex nature of both stress- and reward-related neural processes and highlight the importance of continued efforts to elucidate these pathways.

Considering this complexity in stress and reward processes and given that the time-domain-scoring approach constitutes a relatively broad index of reward processing, encompassing multiple temporally overlapping processes (Weinberg et al., in press), we also examined the spectral characteristics of the ERPs. Consistent with previous literature, loss feedback elicited increased theta power relative to gain feedback, whereas gain feedback elicited increased delta power (Bernat et al., 2015; Foti et al., 2015). Although there was no significant effect of stress on theta power, we observed decreased delta power after stress. These dissociable effects of stress on feedback-locked delta and theta power suggest some specificity in the ways that stress affects brain function. Specifically, previous evidence suggests that the theta component of the reward response may be primarily sensitive to the most basic aspects of reward-related feedback, such as outcome, and may be insensitive to higher-order characteristics, such as experimental context (Bernat et al., 2015; Watts, Bachman, \& Bernat, 2017; Watts \& Bernat, 2018). Conversely, delta activity has been shown to be sensitive to higher-order attributes of reward-related feedback, such as context, magnitude, and expectancy (Bernat et al., 2015; Watts \& Bernat, 2018; Watts et al., 2017), which suggests that delta activity may reflect elaborative processing of feedback stimuli. The present data, therefore, suggest that acute psychosocial stress did not impair basic performance monitoring; rather, it impaired the elaborative processing, and possibly reduced the motivational salience, of both positive and negative feedback.

In addition, the present work contributed to existing literature by examining associations between reward responsivity and HPA-axis functioning in response to acute stress. Contrary to our predictions, we did not demonstrate that delta power after rewards predicted the trajectory of the cortisol response over the course of the stressor (i.e., cortisol reactivity); rather, we found that increased delta power after gains was associated with lower cortisol levels overall in the stress condition but not in the control condition. Nevertheless, these data are consistent with evidence suggesting that the functioning of the neural reward system may be implicated in susceptibility to and buffering from stress (Cabib \& Puglisi-Allegra, 2012; Dedovic, Duchesne, et al., 2009; Heller et al., 2013; Krishnan et al., 2007; 
Pegg et al., 2019; Sandre et al., 2019; Tashjian \& Galván, 2018) and suggest more specifically that a robust neural reward system may be protective against some of the hazardous effects of stress.

Animal and human research has indicated that one avenue through which chronic stress can be detrimental is that prolonged exposure to elevated levels of glucocorticoids (e.g., cortisol) can lead to dendritic atrophy and reductions in neurogenesis (Swaab, Bao, \& Lucassen, 2005). Although evidence indicates that stress may, at least temporarily (Czéh et al., 2001; Van der Hart et al., 2002), alter neural structures involved in reward processing via exposure to glucocorticoids, the present work, and that of others (e.g., Cabib \& Puglisi-Allegra, 2012, Heller et al., 2013, Krishnan et al., 2007), supports the idea that these processes are dynamic. Individuals with existing impairments in neural structures involved in reward processing may be more sensitive to stress and may generate higher levels of cortisol in response to stressful experiences (Corral-Frías, Nadel, Fellous, \& Jacobs, 2016; Dedovic, Duchesne, et al., 2009; Vialou et al., 2010). With the experience of severe or chronic stress, prolonged exposure to high levels of cortisol may then cause further adaptations in these initially susceptible individuals, making them still more vulnerable to the effects of subsequent stressors.

This hypothesis is borne out in the depression literature with kindling or stress-sensitization theories of depression (Post, 1992) and by data suggesting that for successive recurrences of depressive episodes, lower levels of stress are sufficient to catalyze the illness (Monroe \& Harkness, 2005). It is possible, then, that individuals who have initially robust neural reward circuitry are protected against this detrimental spiral by virtue of reduced cortisol output in the face of stress and continued resilience to subsequent stressors. Additional research is needed, however, to explore this possibility and to determine the specific mechanisms by which heightened neural responses to rewards might buffer against the impairing effects of stress. Moreover, a blunted RewP is thought to represent a vulnerability marker for psychopathology (Bress, Foti, Kotov, Klein, \& Hajcak, 2013; Kujawa, Proudfit, \& Klein, 2014; Weinberg, Liu, Hajcak, \& Shankman, 2015), and so if a blunted neural response to rewards is associated with increased stress susceptibility, the data presented here might also point to a possible mechanistic role for this biomarker in the development of psychopathology. Again, however, future research is needed to expand on this proposition.

Given that it is more often chronic exposure to excess glucocorticoids that is associated with the development of mental illness (Lupien, McEwen, Gunnar, \& Heim, 2009), an important consideration when interpreting the present findings is that we implemented a time-limited, acute stressor. This experimental design was motivated by our aims to test whether stress can alter reward processing in a causal way and to assess how neural responses to rewards might be associated with the HPAaxis response to stress; yet it remains unclear how the present work maps on to our understanding of chronic stress. In fact, evidence suggests that acute and chronic stress may have distinct associations with behavioral and neurological responses (Ironside, Kumar, Kang, \& Pizzagalli, 2018). This is an important caveat given that it is chronic stress (i.e., prolonged or repeated exposure to stress) that is thought to be particularly detrimental to mental and physical health outcomes (Juster, McEwen, \& Lupien, 2010; McEwen, 2017). Fruitful next steps in this line of work, therefore, could be to test the persistence of the laboratory-induced stress effects reported here or to examine possible moderating effects of life stress on associations between acute laboratory stressors and neural response to rewards (e.g., Kumar et al., 2015). In addition, evidence suggests that for chronic stress, the type of stressor experienced as well as the period during development at which it was experienced play critical roles in determining its biological and psychosocial consequences (Lupien et al., 2009; Tottenham \& Sheridan, 2010). Data indicating sensitive developmental periods for the effect of stressors suggest it will also be critical to examine these questions across the life span using developmentally appropriate laboratory stress inductions (e.g., Kryski, Smith, Sheikh, Singh, \& Hayden, 2011; Mackrell et al., 2014).

A final consideration with regard to the present study is the use of a sample of men. This was a design decision made in light of evidence that menstrual phase and hormonal contraceptive use have been shown to significantly influence physiological responses to stress (Duchesne \& Pruessner, 2013; Maki et al., 2015; Roche et al., 2013; Villada et al., 2014). However, much of the interest in stress-reward associations stems from efforts to understand risk for stress-related psychopathologies, such as depression and PTSD. Note that depression is a disorder that is approximately twice as common in women as in men (Kessler, 2003), and evidence suggests that impaired reward processing may be more common in women with PTSD than in men with PTSD (Nawijn et al., 2015). Evidence also indicates that there are important sex and gender differences in response to acute stress and that these differences may explain increased vulnerability for mood problems after stress for women specifically (Ali, Cooperman, \& Pruessner, 2015). In addition, some initial work has demonstrated gender differences in associations between stress and reward processing (Lighthall et al., 2012; Nikolova, Bogdan, \& Pizzagalli, 2012). Taken together, this evidence 
suggests that examining sex and gender differences in stress-reward associations is an important avenue for continued study, especially with an eye to better understanding pathways to psychopathology. Nevertheless, some studies that have examined associations between stress and neural response to rewards in the context of clinical symptoms or clinical populations have included men in their samples and have still identified relevant links to psychopathology (Kumar et al., 2015; Pegg et al., 2019). This evidence suggests that the data reported here have important implications for understanding clinical science and serve as a proof of concept for future similar studies in clinical populations including multiple genders.

Overall, the findings presented here highlight the complex nature of associations between physiological responses to stress and neural responses to rewards. Indeed, these data suggest both that acute stress can degrade neural responses to rewards and thus may be a mechanism by which stress leads to psychopathology and also that a robust neural reward system is associated with reduced cortisol output under conditions of stress and thus may be a marker of resilience to stress-related psychopathology. These data advance the understanding of the nature of stress- and reward-response interactions and provide a valuable window into risk and resilience for stress-related psychopathology.

\section{Transparency}

Action Editor: Erin B. Tone

Editor: Scott O. Lilienfeld

Author Contributions

P. Ethridge, A. Weinberg, and J. C. Pruessner developed the study concept, and P. Ethridge, A. Weinberg, N. Ali, and J. C. Pruessner contributed to establishing and implementing the experimental paradigm. Data collection was conducted by P. Ethridge under the supervision of A. Weinberg. P. Ethridge, A. Weinberg, and S. E. Racine performed data analysis and interpretation. P. Ethridge and A. Weinberg drafted the manuscript. All of the authors provided revisions and approved the final version for submission.

Declaration of Conflicting Interests

The author(s) declared that there were no conflicts of interest with respect to the authorship or the publication of this article.

Open Practices

All data have been made publicly available via Open Science Framework and can be accessed at https://osf .io/3fpza. The complete Open Practices Disclosure for this article can be found at http://journals.sagepub.com/doi/ suppl/10.1177/2167702620917463. This article has received the badge for Open Data. More information about the Open Practices badges can be found at https://www.psy chologicalscience.org/publications/badges.

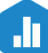

\section{ORCID iD}

Paige Ethridge (D) https://orcid.org/0000-0002-8615-9981

\section{Supplemental Material}

Additional supporting information can be found at http:// journals.sagepub.com/doi/suppl/10.1177/2167702620917463

\section{Notes}

1. To verify that using a separate artifact rejection procedure for time-domain and time-frequency analyses did not affect our results, we compared the $\mathrm{FC}_{\text {avg }}$ time-domain neural responses between 230 and $330 \mathrm{~ms}$ in the gain and loss conditions for Doors 1 and Doors 2 using Pearson's correlations and found that neural responses were highly correlated across artifact-rejection approaches $(r s \geq .97, p s<.001)$.

2. Analysis predicting cortisol response was repeated with the addition of time of testing session (coded as AM $=0, P M=1$ ) as a predictor. Time of testing session significantly predicted cortisol levels in the control group but not in the stress group.

\section{References}

Admon, R., Lubin, G., Rosenblatt, J. D., Stern, O., Kahn, I., Assaf, M., \& Hendler, T. (2013). Imbalanced neural responsivity to risk and reward indicates stress vulnerability in humans. Cerebral Cortex, 23, 28-35. doi:10.1093/cercor/bhr369

Ali, N., Cooperman, C., \& Pruessner, J. (2015). Sex and gender differences in the suppression of the stress systems: A potential link to anxiety and mood disorders? Psychoneuroendocrinology, 61, 63. doi:10.1016/j.psyneuen .2015 .07 .562

Ali, N., Nitschke, J. P., Cooperman, C., \& Pruessner, J. C. (2017). Suppressing the endocrine and autonomic stress systems does not impact the emotional stress experience after psychosocial stress. Psychoneuroendocrinology, 78, 125-130. doi:10.1016/j.psyneuen.2017.01.015

American Psychiatric Association. (2013). Diagnostic and statistical manual of mental disorders (5th ed.). Washington, DC: Author.

Andersen, S. L., \& Teicher, M. H. (2009). Desperately driven and no brakes: Developmental stress exposure and subsequent risk for substance abuse. Neuroscience $\varepsilon$ Biobehavioral Reviews, 33, 516-524. doi:10.1016/j.neu biorev.2008.09.009

Banis, S., Geerligs, L., \& Lorist, M. M. (2014). Acute stress modulates feedback processing in men and women: Differential effects on the feedback-related negativity and theta and beta power. PLOS ONE, 9(4), Article e95690. doi:10.1371/journal.pone.0095690

Banis, S., \& Lorist, M. M. (2012). Acute noise stress impairs feedback processing. Biological Psychology, 91, 163-171. doi:10.1016/j.biopsycho.2012.06.009

Banis, S., \& Lorist, M. M. (2017). The combined effects of menstrual cycle phase and acute stress on rewardrelated processing. Biological Psychology, 125, 130-145. doi:10.1016/j.biopsycho.2017.02.005 
Baskin-Sommers, A. R., \& Foti, D. (2015). Abnormal reward functioning across substance use disorders and major depressive disorder: Considering reward as a transdiagnostic mechanism. International Journal of Psychophysiology, 98, 227-239. doi:10.1016/j.ijpsycho.2015.01.011

Berenbaum, H., \& Connelly, J. (1993). The effect of stress on hedonic capacity. Journal of Abnormal Psychology, 102(3), 474-481.

Berghorst, L. H., Bogdan, R., Frank, M. J., \& Pizzagalli, D. A. (2013). Acute stress selectively reduces reward sensitivity. Frontiers in Human Neuroscience, 7, Article 133. doi: 10.3389/fnhum.2013.00133

Bernat, E. M., Nelson, L. D., \& Baskin-Sommers, A. R. (2015). Time-frequency theta and delta measures index separable components of feedback processing in a gambling task. Psychophysiology, 52, 626-637. doi:10.1111/psyp.12390

Bernat, E. M., Nelson, L. D., Steele, V. R., Gehring, W. J., \& Patrick, C. J. (2011). Externalizing psychopathology and gain-loss feedback in a simulated gambling task: Dissociable components of brain response revealed by time-frequency analysis. Journal of Abnormal Psychology, 120, 352-364.

Birn, R. M., Roeber, B. J., \& Pollak, S. D. (2017). Early childhood stress exposure, reward pathways, and adult decision making. Proceedings of the National Academy of Sciences, USA, 114, 13549-13554. doi:10.1073/pnas.1708791114

Boecker, R., Holz, N. E., Buchmann, A. F., Blomeyer, D., Plichta, M. M., Wolf, I., . . Brandeis, D. (2014). Impact of early life adversity on reward processing in young adults: EEG-fMRI results from a prospective study over 25 years. PLOS ONE, 9(8), Article e104185. doi:10.1371/ journal.pone.0104185

Bogdan, R., \& Pizzagalli, D. A. (2006). Acute stress reduces reward responsiveness: Implications for depression. Biological Psychiatry, 60, 1147-1154.

Bogdan, R., Santesso, D. L., Fagerness, J., Perlis, R. H., \& Pizzagalli, D. A. (2011). Corticotropin-releasing hormone receptor type 1 (CRHR1) genetic variation and stress interact to influence reward learning. Journal of Neuroscience, 31, 13246-13254. doi:10.1523/JNEUROSCI.2661-11.2011

Born, J. M., Lemmens, S. G., Rutters, F., Nieuwenhuizen, A. G., Formisano, E., Goebel, R., \& Westerterp-Plantenga, M. S. (2010). Acute stress and food-related reward activation in the brain during food choice during eating in the absence of hunger. International Journal of Obesity, 34, 172-181. doi:10.1038/ijo.2009.221

Bowers, M., Buzzell, G., Bernat, E., Fox, N., \& Barker, T. (2018). Time-frequency approaches to investigating changes in feedback processing during childhood and adolescence. Psychophysiology, 55(10), Article e13208. doi:10.1111/psyp.13208

Bress, J. N., Foti, D., Kotov, R., Klein, D. N., \& Hajcak, G. (2013). Blunted neural response to rewards prospectively predicts depression in adolescent girls. Psychophysiology, 50, 74-81. doi:10.1111/j.1469-8986.2012.01485.x

Bress, J. N., Meyer, A., \& Proudfit, G. H. (2015). The stability of the feedback negativity and its relationship with depression during childhood and adolescence. Development and Psychopathology, 27(4 Pt1), 1285-1294. doi:10.1017/ S0954579414001400
Bryk, A. S., \& Raudenbush, S. W. (1987). Application of hierarchical linear models to assessing change. Psychological Bulletin, 101, 147-158. doi:10.1037/0033-2909.101.1.147

Bylsma, L. M., Morris, B. H., \& Rottenberg, J. (2008). A meta-analysis of emotional reactivity in major depressive disorder. Clinical Psychology Review, 28, 676-691. doi:10.1016/j.cpr.2007.10.001

Cabib, S., \& Puglisi-Allegra, S. (2012). The mesoaccumbens dopamine in coping with stress. Neuroscience $\mathcal{E}$ Biobehavioral Reviews, 36, 79-89. doi:10.1016/j.neubio rev.2011.04.012

Casement, M. D., Guyer, A. E., Hipwell, A. E., McAloon, R. L., Hoffmann, A. M., Keenan, K. E., \& Forbes, E. E. (2014). Girls' challenging social experiences in early adolescence predict neural response to rewards and depressive symptoms. Developmental Cognitive Neuroscience, 8, 18-27. doi:10.1016/j.den.2013.12.003

Cohen, M. X., Elger, C. E., \& Ranganath, C. (2007). Reward expectation modulates feedback-related negativity and EEG spectra. NeuroImage, 35, 968-978. doi:10.1016/j .neuroimage.2006.11.056

Corral-Frías, N. S., Nadel, L., Fellous, J.-M., \& Jacobs, W. J. (2016). Behavioral and self-reported sensitivity to reward are linked to stress-related differences in positive affect. Psychoneuroendocrinology, 66, 205-213. doi:10.1016/j .psyneuen.2016.01.012

Czéh, B., Michaelis, T., Watanabe, T., Frahm, J., De Biurrun, G., Van Kampen, M., Bartolomucci, A., \& Fuchs, E. (2001). Stress-induced changes in cerebral metabolites, hippocampal volume, and cell proliferation are prevented by antidepressant treatment with tianeptine. Proceedings of the National Academy of Sciences, USA, 98, 12796-12801. doi:10.1073/pnas. 211427898

Dawe, S., Gullo, M. J., \& Loxton, N. J. (2004). Reward drive and rash impulsiveness as dimensions of impulsivity: Implications for substance misuse. Addictive Behaviors, 29, 1389-1405. doi:10.1016/j.addbeh.2004.06.004

Dedovic, K., Duchesne, A., Andrews, J., Engert, V., \& Pruessner, J. C. (2009). The brain and the stress axis: The neural correlates of cortisol regulation in response to stress. NeuroImage, 47, 864-871.

Dedovic, K., Renwick, R., Mahani, N. K., Engert, V., Lupien, S. J., \& Pruessner, J. C. (2005). The Montreal Imaging Stress Task: Using functional imaging to investigate the effects of perceiving and processing psychosocial stress in the human brain. Journal of Psychiatry and Neuroscience, 30, 319-325.

Dedovic, K., Wadiwalla, M., Engert, V., \& Pruessner, J. C. (2009). The role of sex and gender socialization in stress reactivity. Developmental Psychology, 45, 45-55. doi:10 $.1037 / \mathrm{a} 0014433$

Dickerson, S. S., \& Kemeny, M. E. (2004). Acute stressors and cortisol responses: A theoretical integration and synthesis of laboratory research. Psychological Bulletin, 130, 355-391. doi:10.1037/0033-2909.130.3.355

Dierolf, A. M., Fechtner, J., Bohnke, R., Wolf, O. T., \& Naumann, E. (2017). Influence of acute stress on response inhibition in healthy men: An ERP study. Psychophysiology, 54, 684-695. doi:10.1111/psyp. 12826 
Dillon, D. G., Holmes, A. J., Birk, J. L., Brooks, N., LyonsRuth, K., \& Pizzagalli, D. A. (2009). Childhood adversity is associated with left basal ganglia dysfunction during reward anticipation in adulthood. Biological Psychiatry, 66, 206-213. doi:10.1016/j.biopsych.2009.02.019

Dressendörfer, R., Kirschbaum, C., Rohde, W., Stahl, F., \& Strasburger, C. (1992). Synthesis of a cortisol-biotin conjugate and evaluation as a tracer in an immunoassay for salivary cortisol measurement. The Journal of Steroid Biochemistry and Molecular Biology, 43, 683-692. doi:10 .1016/0960-0760(92)90294-S

Duchesne, A., \& Pruessner, J. C. (2013). Association between subjective and cortisol stress response depends on the menstrual cycle phase. Psychoneuroendocrinology, 38, 3155-3159.

Engert, V., Efanov, S. I., Duchesne, A., Vogel, S., Corbo, V., \& Pruessner, J. C. (2013). Differentiating anticipatory from reactive cortisol responses to psychosocial stress. Psychoneuroendocrinology, 38, 1328-1337. doi:10.1016/j .psyneuen.2012.11.018

Eriksen, B. A., \& Eriksen, C. W. (1974). Effects of noise letters upon the identification of a target letter in a nonsearch task. Perception E Psychophysics, 16, 143-149.

Ethridge, P., Sandre, A., Dirks, M. A., \& Weinberg, A. (2018). Past-year relational victimization is associated with a blunted neural response to rewards in emerging adults. Social Cognitive and Affective Neuroscience, 13, 12591267. doi:10.1093/scan/nsy091

Ethridge, P., \& Weinberg, A. (2018). Psychometric properties of neural responses to monetary and social rewards across development. International Journal of Psychophysiology, 132, 311-322. doi:j.ijpsycho.2018.01.011

Foti, D., \& Hajcak, G. (2012). Genetic variation in dopamine moderates neural response during reward anticipation and delivery: Evidence from event-related potentials. Psychophysiology, 49, 617-626.

Foti, D., Weinberg, A., Bernat, E. M., \& Proudfit, G. H. (2015). Anterior cingulate activity to monetary loss and basal ganglia activity to monetary gain uniquely contribute to the feedback negativity. Clinical Neurophysiology, 126, 1338-1347. doi:10.1016/j.clinph.2014.08.025

Frewen, P. A., Dozois, D. J., \& Lanius, R. A. (2012). Assessment of anhedonia in psychological trauma: Psychometric and neuroimaging perspectives. European Journal of Psychotraumatology, 3(1), 8587. doi:10.3402/ejpt.v3i0.8587

Gaffrey, M. S., Barch, D. M., Bogdan, R., Farris, K., Petersen, S. E., \& Luby, J. L. (2018). Amygdala reward reactivity mediates the association between preschool stress response and depression severity. Biological Psychiatry, 83, 128-136. doi:10.1016/j.biopsych.2017.08.020

Gratton, G., Coles, M. G., \& Donchin, E. (1983). A new method for off-line removal of ocular artifact. Electroencephalography and Clinical Neurophysiology, 55, 468484. doi:10.1016/0013-4694(83)90135-9

Guyer, A. E., Kaufman, J., Hodgdon, H. B., Masten, C. L., Jazbec, S., Pine, D. S., \& Ernst, M. (2006). Behavioral alterations in reward system function: The role of childhood maltreatment and psychopathology. Journal of the American Academy of Child \& Adolescent Psychiatry, 45, 1059-1067. doi:10.1097/01.chi.0000227882.50404.11
Hammen, C. (1991). Generation of stress in the course of unipolar depression. Journal of Abnormal Psychology, 100, 555-561. doi:10.1037/0021-843X.100.4.555

Hammen, C. (2006). Stress generation in depression: Reflections on origins, research, and future directions. Journal of Clinical Psychology, 62, 1065-1082.

Hanson, J. L., Hariri, A. R., \& Williamson, D. E. (2015). Blunted ventral striatum development in adolescence reflects emotional neglect and predicts depressive symptoms. Biological Psychiatry, 78, 598-605. doi:10.1016/j .biopsych.2015.05.010

Hanson, J. L., Albert, D., Iselin, A.-M. R., Carre, J. M., Dodge, K. A., \& Hariri, A. R. (2015). Cumulative stress in childhood is associated with blunted reward-related brain activity in adulthood. Social Cognitive and Affective Neuroscience, 11, 405-412.

Hanson, J. L., Knodt, A. R., Brigidi, B. D., \& Hariri, A. R. (2018). Heightened connectivity between the ventral striatum and medial prefrontal cortex as a biomarker for stress-related psychopathology: Understanding interactive effects of early and more recent stress. Psychological Medicine, 48, 1835-1843. doi:10.1017/S0033291717003348

Heller, A. S., van Reekum, C. M., Schaefer, S. M., Lapate, R. C., Radler, B. T., Ryff, C. D., \& Davidson, R. J. (2013). Sustained striatal activity predicts eudaimonic well-being and cortisol output. Psychological Science, 24, 2191-2200. doi:10.1177/0956797613490744

Herman, J. P., Figueiredo, H., Mueller, N. K., Ulrich-Lai, Y., Ostrander, M. M., Choi, D. C., \& Cullinan, W. E. (2003). Central mechanisms of stress integration: Hierarchical circuitry controlling hypothalamo-pituitary-adrenocortical responsiveness. Frontiers in Neuroendocrinology, 24(3), 151-180. doi:10.1016/j.yfrne.2003.07.001

Hollon, N. G., Burgeno, L. M., \& Phillips, P. E. (2015). Stress effects on the neural substrates of motivated behavior. Nature Neuroscience, 18, 1405-1412. doi:10.1038/nn.4114

Ironside, M., Kumar, P., Kang, M.-S., \& Pizzagalli, D. A. (2018). Brain mechanisms mediating effects of stress on reward sensitivity. Current Opinion in Behavioral Sciences, 22, 106-113. doi:10.1016/j.cobeha.2018.01.016

Juster, R.-P., McEwen, B. S., \& Lupien, S. J. (2010). Allostatic load biomarkers of chronic stress and impact on health and cognition. Neuroscience \& Biobehavioral Reviews, 35, 2-16. doi:10.1016/j.neubiorev.2009.10.002

Kashdan, T. B., Elhai, J. D., \& Frueh, B. C. (2006). Anhedonia and emotional numbing in combat veterans with PTSD. Behaviour Research and Therapy, 44, 457-467. doi:10.1016/j.brat.2005.03.001

Kessler, R. C. (2003). Epidemiology of women and depression. Journal of Affective Disorders, 74, 5-13.

Kinner, V. L., Wolf, O. T., \& Merz, C. J. (2016). Cortisol alters reward processing in the human brain. Hormones and Behavior, 84, 75-83. doi:10.1016/j.yhbeh.2016.05.005

Kirschbaum, C., \& Hellhammer, D. H. (2000). Salivary cortisol. In G. Fink (Ed.), Encyclopedia of stress (Vol. 3, pp. 379-384). San Diego, CA: Academic Press.

Kollins, S. H. (2003). Delay discounting is associated with substance use in college students. Addictive Behaviors, 28, 1167-1173. doi:10.1016/S0306-4603(02)00220-4 
Krishnan, V., Han, M.-H., Graham, D. L., Berton, O., Renthal, W., Russo, S. J., . . . Lagace, D. C. (2007). Molecular adaptations underlying susceptibility and resistance to social defeat in brain reward regions. Cell, 131, 391-404. doi:10.1016/j.cell.2007.09.018

Kryski, K. R., Smith, H. J., Sheikh, H. I., Singh, S. M., \& Hayden, E. P. (2011). Assessing stress reactivity indexed via salivary cortisol in preschool-aged children. Psychoneuroendocrinology, 36, 1127-1136. doi:10.1016/j .psyneuen.2011.02.003

Kudielka, B. M., Kirschbaum, W. C., \& Hellhammer, D. H. (2007). Trier Social Stress Test (2nd ed.). In G. Fink (Ed.), Encyclopedia of stress (pp. 776-781). New York, NY: Academic Press.

Kujawa, A., Proudfit, G. H., \& Klein, D. N. (2014). Neural reactivity to rewards and losses in offspring of mothers and fathers with histories of depressive and anxiety disorders. Journal of Abnormal Psychology, 123, 287-297. doi:10.1037/a0036285

Kumar, P., Berghorst, L. H., Nickerson, L. D., Dutra, S. J., Goer, F., Greve, D., \& Pizzagalli, D. A. (2014). Differential effects of acute stress on anticipatory and consummatory phases of reward processing. Journal of Neuroscience, 266, 1-12. doi:10.1016/j.neuroscience.2014.01.058

Kumar, P., Slavich, G. M., Berghorst, L. H., Treadway, M. T., Brooks, N. H., Dutra, S. J., . . . Pizzagalli, D. A. (2015). Perceived life stress exposure modulates reward-related medial prefrontal cortex responses to acute stress in depression. Journal of Affective Disorders, 180, 104-111. doi:10.1016/j.jad.2015.03.035

Levinson, A. R., Speed, B. C., Infantolino, Z. P., \& Hajcak, G. (2017). Reliability of the electrocortical response to gains and losses in the doors task. Psychophysiology, 54, 601607. doi:10.1111/psyp.12813

Lighthall, N. R., Gorlick, M. A., Schoeke, A., Frank, M. J., \& Mather, M. (2013). Stress modulates reinforcement learning in younger and older adults. Psychology and Aging, 28, 35-46. doi:10.1037/a0029823

Lighthall, N. R., Sakaki, M., Vasunilashorn, S., Nga, L., Somayajula, S., Chen, E. Y., . . Mather, M. (2012). Gender differences in reward-related decision processing under stress. Social Cognitive and Affective Neuroscience, 7 , 476-484.

Lincoln, S. H., Pisoni, A., Bondy, E., Kumar, P., Singleton, P., Hajcak, G., . . Auerbach, R. P. (2019). Altered reward processing following an acute social stressor in adolescents. PLOS ONE, 14(1), Article e0209361. doi:10.1371/journal .pone.0209361

Liu, R. T., \& Alloy, L. B. (2010). Stress generation in depression: A systematic review of the empirical literature and recommendations for future study. Clinical Psychology Review, 30, 582-593. doi:10.1016/j.cpr.2010.04.010

Liu, W.-h., Chan, R. C., Wang, L.-z., Huang, J., Cheung, E. F., Gong, Q.-y., \& Gollan, J. K. (2011). Deficits in sustaining reward responses in subsyndromal and syndromal major depression. Progress in Neuro-Psychopharmacology and Biological Psychiatry, 35, 1045-1052. doi:10.1016/j .pnpbp.2011.02.018
Luking, K. R., Nelson, B. D., Infantolino, Z. P., Sauder, C. L., \& Hajcak, G. (2017). Internal consistency of functional magnetic resonance imaging and electroencephalography measures of reward in late childhood and early adolescence. Biological Psychiatry: Cognitive Neuroscience and Neuroimaging, 2, 289-297. doi:10.1016/j.bpsc.2016.12.004

Lupien, S. J., McEwen, B. S., Gunnar, M. R., \& Heim, C. (2009). Effects of stress throughout the lifespan on the brain, behaviour and cognition. Nature Reviews Neuroscience, 10, 434-445.

Mackin, D. M., Kotov, R., Perlman, G., Nelson, B. D., Goldstein, B. L., Hajcak, G., \& Klein, D. N. (2019). Reward processing and future life stress: Stress generation pathway to depression. Journal of Abnormal Psychology, 128, 305-314. doi:10.1037/abn0000427

Mackrell, S. V., Sheikh, H. I., Kotelnikova, Y., Kryski, K. R., Jordan, P. L., Singh, S. M., \& Hayden, E. P. (2014). Child temperament and parental depression predict cortisol reactivity to stress in middle childhood. Journal of Abnormal Psychology, 123, 106-116. doi:10.1037/a0035612

Maki, P. M., Mordecai, K. L., Rubin, L. H., Sundermann, E., Savarese, A., Eatough, E., \& Drogos, L. (2015). Menstrual cycle effects on cortisol responsivity and emotional retrieval following a psychosocial stressor. Hormones and Behavior, 74, 201-208. doi:10.1016/j.yhbeh.2015.06.023

Mather, M., \& Lighthall, N. R. (2012). Risk and reward are processed differently in decisions made under stress. Current Directions in Psychological Science, 21, 36-41. doi:10.1177/0963721411429452

McEwen, B. S. (2017). Neurobiological and systemic effects of chronic stress. Chronic Stress, 1, 1-11. doi:10.1177/ 2470547017692328

Mehta, M. A., Gore-Langton, E., Golembo, N., Colvert, E., Williams, S. C., \& Sonuga-Barke, E. (2010). Hyporesponsive reward anticipation in the basal ganglia following severe institutional deprivation early in life. Journal of Cognitive Neuroscience, 22, 2316-2325. doi:10.1162/jocn.2009.21394

Miller, R., Plessow, F., Kirschbaum, C., \& Stalder, T. (2013). Classification criteria for distinguishing cortisol responders from nonresponders to psychosocial stress: Evaluation of salivary cortisol pulse detection in panel designs. Psychosomatic Medicine, 75, 832-840. doi:10.1097/PSY.0000 000000000002

Monroe, S. M., \& Harkness, K. L. (2005). Life stress, the "kindling" hypothesis, and the recurrence of depression: considerations from a life stress perspective. Psychological Review, 112(2), 417-445.

Morris, B. H., \& Rottenberg, J. (2015). Heightened reward learning under stress in generalized anxiety disorder: A predictor of depression resistance? Journal of Abnormal Psychology, 124, 115-127. doi:10.1037/a0036934

Myin-Germeys, I., van Os, J., Schwartz, J. E., Stone, A. A., \& Delespaul, P. A. (2001). Emotional reactivity to daily life stress in psychosis. Archives of General Psychiatry, 58, 1137-1144. doi:10.1001/archpsyc.58.12.1137

Nawijn, L., van Zuiden, M., Frijling, J. L., Koch, S. B., Veltman, D. J., \& Olff, M. (2015). Reward functioning in PTSD: A systematic review exploring the mechanisms underlying 
anhedonia. Neuroscience \& Biobehavioral Reviews, 51, 189-204. doi:10.1016/j.neubiorev.2015.01.019

Nikolova, Y., Bogdan, R., \& Pizzagalli, D. A. (2012). Perception of a naturalistic stressor interacts with 5-HTTLPR/rs25531 genotype and gender to impact reward responsiveness. Neuropsychobiology, 65, 45-54. doi:10.1159/000329105

Noble, E. (2000). Addiction and its reward process through polymorphisms of the D2 dopamine receptor gene: A review. European Psychiatry, 15, 79-89. doi:10.1016/ S0924-9338(00)00208-X

Ossewaarde, L., Qin, S., Van Marle, H. J., van Wingen, G. A., Fernández, G., \& Hermans, E. J. (2011). Stress-induced reduction in reward-related prefrontal cortex function. NeuroImage, 55, 345-352. doi:10.1016/j.neuroim age.2010.11.068

Pegg, S. N., Ethridge, P., Shields, G. S., Slavich, G. M., Weinberg, A., \& Kujawa, A. (2019). Blunted social reward responsiveness moderates the effect of lifetime social stress exposure on depressive symptoms. Frontiers in Behavioral Neuroscience, 13, Article 178. doi:10.3389/ fnbeh.2019.00178

Petzold, A., Plessow, F., Goschke, T., \& Kirschbaum, C. (2010). Stress reduces use of negative feedback in a feedback-based learning task. Behavioral Neuroscience, 124, 248-255. doi:10.1037/a0018930

Pizzagalli, D. A. (2014). Depression, stress, and anhedonia: Toward a synthesis and integrated model. Annual Review of Clinical Psychology, 10, 393-423.

Pizzagalli, D. A., Bogdan, R., Ratner, K. G., \& Jahn, A. L. (2007). Increased perceived stress is associated with blunted hedonic capacity: Potential implications for depression research. Behaviour Research and Therapy, 45, 2742-2753. doi:10.1016/j.brat.2007.07.013

Porcelli, A. J., Lewis, A. H., \& Delgado, M. R. (2012). Acute stress influences neural circuits of reward processing. Frontiers in Neuroscience, 6, Article 157. doi:10.3389/fnins .2012 .00157

Post, R. M. (1992). Transduction of psychosocial stress into the neurobiology of recurrent affective disorder. The American Journal of Psychiatry, 149, 999-1010.

Proudfit, G. H. (2015). The reward positivity: From basic research on reward to a biomarker for depression. Psychophysiology, 52, 449-459.

Pruessner, J. C., Dedovic, K., Khalili-Mahani, N., Engert, V., Pruessner, M., Buss, C., . . Lupien, S. (2008). Deactivation of the limbic system during acute psychosocial stress: Evidence from positron emission tomography and functional magnetic resonance imaging studies. Biological Psychiatry, 63, 234-240. doi:10.1016/j.bio psych.2007.04.041

Radua, J., Schmidt, A., Borgwardt, S., Heinz, A., Schlagenhauf, F., McGuire, P., \& Fusar-Poli, P. (2015). Ventral striatal activation during reward processing in psychosis: A neurofunctional meta-analysis. JAMA Psychiatry, 72, 12431251. doi:10.1001/jamapsychiatry.2015.2196

Roche, D. J., King, A. C., Cohoon, A. J., \& Lovallo, W. R. (2013). Hormonal contraceptive use diminishes salivary cortisol response to psychosocial stress and naltrexone in healthy women. Pharmacology Biochemistry and Behavior, 109, 84-90. doi:10.1016/j.pbb.2013.05.007

Sandre, A., Bagot, R., \& Weinberg, A. (2019). Blunted neural response to appetitive images prospectively predicts symptoms of depression, and not anxiety, during the transition to university. Biological Psychology, 145, 31-34. doi:10.1016/j.biopsycho.2019.04.001

Schwabe, L., Haddad, L., \& Schachinger, H. (2008). HPA axis activation by a socially evaluated cold-pressor test. Psychoneuroendocrinology, 33, 890-895. doi:10.1016/j .psyneuen.2008.03.001

Sesack, S. R., \& Grace, A. A. (2010). Cortico-basal ganglia reward network: Microcircuitry. Neuropsychopharmacology, 35, 27-47. doi:10.1038/npp.2009.93

Singer, J. D., Willett, J. B., \& Willett, J. B. (2003). Applied longitudinal data analysis: Modeling change and event occurrence. Oxford, England: Oxford University Press.

Starcke, K., Wolf, O. T., Markowitsch, H. J., \& Brand, M. (2008). Anticipatory stress influences decision making under explicit risk conditions. Behavioral Neuroscience, 122, 1352-1360. doi:10.1037/a0013281

Strauss, G. P., Waltz, J. A., \& Gold, J. M. (2013). A review of reward processing and motivational impairment in schizophrenia. Schizophrenia Bulletin, 40 (Suppl. 2), S107-S116. doi:10.1093/schbul/sbt197

Swaab, D. F., Bao, A.-M., \& Lucassen, P. J. (2005). The stress system in the human brain in depression and neurodegeneration. Ageing Research Reviews, 4, 141-194. doi: 10.1016/j.arr.2005.03.003

Tashiian, S. M., \& Galván, A. (2018). The role of mesolimbic circuitry in buffering election-related distress. Journal of Neuroscience, 38, 2887-2898. doi:10.1523/ JNEUROSCI.2470-17.2018

Tottenham, N., \& Sheridan, M. A. (2010). A review of adversity, the amygdala and the hippocampus: A consideration of developmental timing. Frontiers in Human Neuroscience, 3, Article 68. doi:10.3389/neuro.09.068.2009

Treadway, M. T., Admon, R., Arulpragasam, A. R., Mehta, M., Douglas, S., Vitaliano, G., . . Pizzagalli, D. A. (2017). Association between interleukin-6 and striatal prediction-error signals following acute stress in healthy female participants. Biological Psychiatry, 82, 570-577. doi:10.1016/j.biopsych.2017.02.1183

Treadway, M. T., Buckholtz, J. W., \& Zald, D. (2013). Perceived stress predicts altered reward and loss feedback processing in medial prefrontal cortex. Frontiers in Human Neuroscience, 7, Article 180. doi:10.3389/fnhum .2013 .00180

Van de Vijver, I., Ridderinkhof, K. R., \& Cohen, M. X. (2011). Frontal oscillatory dynamics predict feedback learning and action adjustment. Journal of Cognitive Neuroscience, 23, 4106-4121. doi:10.1162/jocn_a_00110

Van der Hart, M. G., Czéh, B., De Biurrun, G., Michaelis, T., Watanabe, T., Natt, O., . . Fuchs, E. (2002). Substance $\mathrm{P}$ receptor antagonist and clomipramine prevent stressinduced alterations in cerebral metabolites, cytogenesis in the dentate gyrus and hippocampal volume. Molecular Psychiatry, 7, 933-941. doi:10.1038/sj.mp.4001130 
Van Winkel, R., Stefanis, N. C., \& Myin-Germeys, I. (2008). Psychosocial stress and psychosis. A review of the neurobiological mechanisms and the evidence for genestress interaction. Schizophrenia Bulletin, 34, 1095-1105. doi:10.1093/schbul/sbn101

Vialou, V., Robison, A. J., LaPlant, Q. C., Covington III, H. E., Dietz, D. M., Ohnishi, Y. N., . . Wallace, D. L. (2010). $\triangle \mathrm{FosB}$ in brain reward circuits mediates resilience to stress and antidepressant responses. Nature Neuroscience, 13, 745-752. doi:10.1038/nn.2551

Vidal-Ribas, P., Benson, B., Vitale, A. D., Keren, H., Harrewijn, A., Fox, N. A., . . Stringaris, A. (2019). Bidirectional associations between stress and reward processing in children and adolescents: A longitudinal neuroimaging study. Biological Psychiatry: Cognitive Neuroscience and Neuroimaging, 4, 893-901. doi:10.1016/j.bpsc.2019.05.012

Villada, C., Hidalgo, V., Almela, M., Mastorci, F., Sgoifo, A., \& Salvador, A. (2014). Coping with an acute psychosocial challenge: Behavioral and physiological responses in young women. PLOS ONE, 9(12), Article e114640. doi:10.1371/journal.pone.0114640

Watts, A. T., Bachman, M. D., \& Bernat, E. M. (2017). Expectancy effects in feedback processing are explained primarily by time-frequency delta not theta. Biological Psychology, 129, 242-252.

Watts, A. T., \& Bernat, E. M. (2018). Effects of reward context on feedback processing as indexed by time-frequency analysis. Psychophysiology, 55(9), Article e13195. doi:10.1111/psyp.13195

Webb, C. A., Auerbach, R. P., Bondy, E., Stanton, C. H., Foti, D., \& Pizzagalli, D. A. (2017). Abnormal neural responses to feedback in depressed adolescents. Journal of Abnormal Psychology, 126, 19-31. doi:10.1037/abn0000228

Weinberg, A., Ethridge, P., Ait Oumeziane, B., \& Foti, D. (in press). Time frequency analyses in event-related potential methodologies. In P. Gable \& E. M. Bernat (Eds.), Oxford handbook of human EEG frequency analysis. Oxford, England: Oxford University Press.

Weinberg, A., Liu, H., Hajcak, G., \& Shankman, S. A. (2015). Blunted neural response to rewards as a vulnerability factor for depression: Results from a family study. Journal of Abnormal Psychology, 124, 878-889. doi:10.1037/abn0000081

Whitton, A. E., Treadway, M. T., \& Pizzagalli, D. A. (2015). Reward processing dysfunction in major depression, bipolar disorder and schizophrenia. Current Opinion in Psychiatry, 28, 7-12. doi:10.1097/YCO.0000000000000122 